\title{
From data compilation to model validation: A comprehensive analysis of a full deep-sea ecosystem model of the Chatham Rise
}

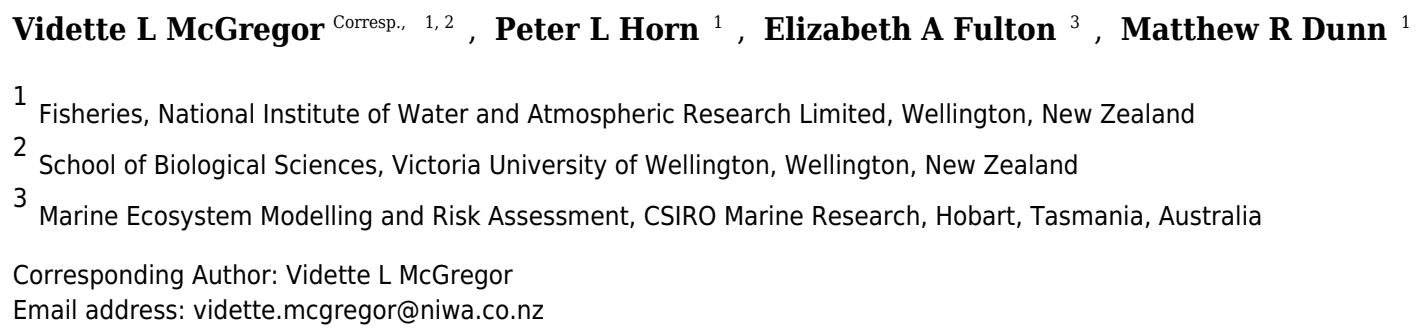

The Chatham Rise is a highly productive deep-sea ecosystem that supports numerous substantial commercial fisheries, and is a likely candidate for an ecosystem based approach to fisheries management in New Zealand. We present the first end-to-end ecosystem model of the Chatham Rise, which is also to be best of our knowledge, the first end-to-end ecosystem model of any deep-sea ecosystem. We describe the process of data compilation through to model validation and analyse the importance of knowledge gaps with respect to model dynamics and results. The model produces very similar results to fisheries stock assessment models for key fisheries species, and the population dynamics and system interactions are realistic. Confidence intervals based on bootstrapping oceanographic variables are produced. The model components that have knowledge gaps and are most likely to influence model results were oceanographic variables, and the aggregate species groups 'seabird' and 'cetacean other'. We recommend applications of the model, such as forecasting biomasses under various fishing regimes, include alternatives that vary these components. 'seabird' and 'cetacean other'. We recommend applications of the model, such as forecasting biomasses under various fishing regimes, include alternatives that vary these components. 
2 From data compilation to model validation: A comprehensive

3 analysis of a full deep-sea ecosystem model of the Chatham ${ }_{4}$ Rise

5

${ }_{6}$ Vidette L. McGregor ${ }^{1,2}$, Peter L. Horn ${ }^{1}$, Elizabeth A. Fulton ${ }^{3}$, Matthew R. Dunn $^{1}$

7

${ }_{8}^{1}$ Fisheries, National Institute of Water and Atmospheric Research Limited, Wellington, New Zealand

$9 \quad{ }^{2}$ School of Biological Sciences, Victoria University, Wellington, New Zealand

${ }_{10}^{3}$ Marine Ecosystem Modelling and Rsik Assessment, CSIRO Marine Research, Hobart, Tasmania,

11 Australia

12

13

14 Corresponding Author:

${ }_{15}$ Vidette McGregor ${ }^{1,2}$ 


\begin{abstract}
The Chatham Rise is a highly productive deep-sea ecosystem that supports numerous substantial commercial fisheries, and is a likely candidate for an ecosystem based approach to fisheries management in New Zealand. We present the first end-to-end ecosystem model of the Chatham Rise, which is also to be best of our knowledge, the first end-to-end ecosystem model of any deep-sea ecosystem. We describe the process of data compilation through to model validation and analyse the importance of knowledge gaps with respect to model dynamics and results. The model produces very similar results to fisheries stock assessment models for key fisheries species, and the population dynamics and system interactions are realistic. Confidence intervals based on bootstrapping oceanographic variables are produced. The model components that have knowledge gaps and are most likely to influence model results were oceanographic variables, and the aggregate species groups 'seabird' and 'cetacean other'. We recommend applications of the model, such as forecasting biomasses under various fishing regimes, include alternatives that vary these components.
\end{abstract}

\title{
1 Introduction
}

The goal of incorporating a holistic approach to understanding the system-wide repercussions of how we manage our marine resources is admirable and ambitious (Long et al. (2015), Link and Browman (2017)). Ecosystem Based Management (EBM) requires a range of tools, often including ecosystem models (Smith et al. (2017), Stecken and Failler (2016)). Within ecosystems there are many processes at play, and the models developed to support EBM vary in scope and complexity (Plagányi (2007), Fulton (2010), Collie et al. (2016)). End-to-end ecosystem models that can deal with bottom-up and top-down system controls have become popular for exploring scenarios involving human induced impacts including fishing and climate change (Rose, 2012).

The body responsible for fisheries management in New Zealand, Fisheries New Zealand, is seeking to move away from single species management towards a more ecosystem approach, both to fulfil Fisheries Act obligations and Marine Stewardship Council (MSC) expectations (Ministry for Primary Industries (2008), Marine Stewardship Council (2014)). The Chatham Rise is the location of several nationally important MSC certified fisheries (Deepwater Group, 2018), and a growing understanding of trophic interactions exists there (Stevens et al. (2011b), Dunn et al. (2009)).

Chatham Rise is a submarine ridge running eastwards for about $1000 \mathrm{~km}$ from the east coast of South Island, New Zealand, rising up from depths of about $3000 \mathrm{~m}$, to about $50 \mathrm{~m}$ at 
the western end, and sea level around the Chatham Islands at the eastern end (Figure 1). The subtropical front (STF), a relatively broad permanent feature where warmer, more saline, and nutrient poor subtropical water from the north meets nutrient rich subantarctic water from the south, extends up the east coast of South Island, and then eastwards along Chatham Rise (Heath (1985), Uddstrom and Oien (1999)). The demersal fish assemblage on Chatham Rise has the highest fish species richness in New Zealand waters (Leathwick et al. 2006). The range of habitats and depths, and the influence of the STF, are expected to provide a wide variety of foraging opportunities for demersal and pelagic organisms.

The Chatham Rise is perhaps New Zealand's most productive fishing ground. It supports substantial commercial fisheries for finfish and invertebrates, with notable examples being: trawl fisheries for hoki (Macruronus novaezelandiae), orange roughy (Hoplostethus atlanticus), hake (Merluccius australis), and black and smooth oreos (Allocyttus niger, Pseudocyttus maculatus); a longline fishery for ling (Genypterus blacodes); and a potting fishery for rock lobster (Jasus edwardsii) (Ministry for Primary Industries 2014).

Analyses of trawl survey series and commercial fishery catch rates have shown that marked variations over time have occurred in the relative abundance of some common species on Chatham Rise, e.g., hoki, hake, orange roughy, scampi (Metanephrops challengeri), and rock lobster (Maunder and Starr, 1995; Dunn et al., 2008; Stevens et al., 2017). Some factors driving these fluctuations have been identified (i.e., high exploitation levels, variation in recruitment), but there will certainly be other physical and biological factors that will influence animal behaviour and survivability, resulting in changes to the ecosystem. A knowledge of how particular biological and ecological changes could affect the abundance and distribution of species will usefully inform the management of those species.

In an ecosystem, nothing exists independently. When assessing biological risks, it is difficult to conceptualise risk to the whole system. A system-level model within which different scenarios can be explored is an extremely valuable tool for gaining conceptual understanding of economic and biological risks for a whole system, as well as for individual parts.

Atlantis is an end-to-end ecosystem modelling approach that can be used to create an environment in which different scenarios can be played out to test for different results and learn how a system may be reacting to changes within it. Reviewed as one of the best modelling frameworks for exploring 'what-if' type questions (Plagányi, 2007), it includes the ability to compare social, conservation, and economic outcomes. With sufficient data, this modelling approach can be extremely useful for management strategy evaluation (Plagányi, 2007), and has been applied to multiple marine systems (from single bays to millions of square kilometres) in Australia, the United States, Europe, and South Africa (Savina et al. (2005), Fulton et al. (2007), Link et al. (2010), Ainsworth et al. (2015), Smith et al. (2015), Sturludottir et al. 
(2018), Ortega-Cisneros et al. (2017)). Atlantis is a deterministic simulation model such that for a given parameter set and model specification, the model outputs are identical. Atlantis models are too complex to statistically fit to observations, although subsets of key parameters can be estimated using statistical methods outside of the model. Analysing and understanding the model dynamics and potential weaknesses is essential before the model can be used to learn about the system.

In this paper, we describe the first end-to-end ecosystem model for the Chatham Rise, New Zealand (hereafter referred to as CRAM). We present analyses of the model, comparing its state and dynamics to current knowledge. We identify and assess the likely influence of current knowledge gaps and uncertainties.

In developing such models, knowledge gaps become evident, and we are provided with the opportunity to analyse the importance of these gaps, thus guiding direction of future research. The model was assessed for single species dynamics and inter-species connectivity. We conducted a skill assessment on species groups for which we have surveys capable of indexing abundance, and compared biomass trends as the model responded to historical fishing for species groups that have stock assessments or reliable catch per unit effort (CPUE) indices. We simulated changes in biomass for each species group and analysed responses throughout the system. This latter part formed the basis for analysing influence and importance of knowledge gaps, and where a species group performed poorly in the skill assessment it often highlighted a knowledge gap.

\section{Methodological Approach}

The process of developing this model was not linear, but rather iterative and incremental. There were five main stages to the development, each of which was re-visited until we were satisfied with the performance of the model and our understanding of its dynamics. The main stages can be summarised as:

1.) Data and model inputs were collated and defined.

2.) The base historical model was calibrated without fishing such that this model had stable biomass trajectories over the 1900-2016 model period, realistic diets, growth rates, natural mortalities.

3.) Sensitivity analyses were carried out with respect to oceanographic variables and simulations aimed at understanding connectivity and influence between the species functional groups.

4.) Fishing was included in the model using forced catch removals.

5.) Skill assessment and comparisons to abundance indices and biomass estimates were carried out. 


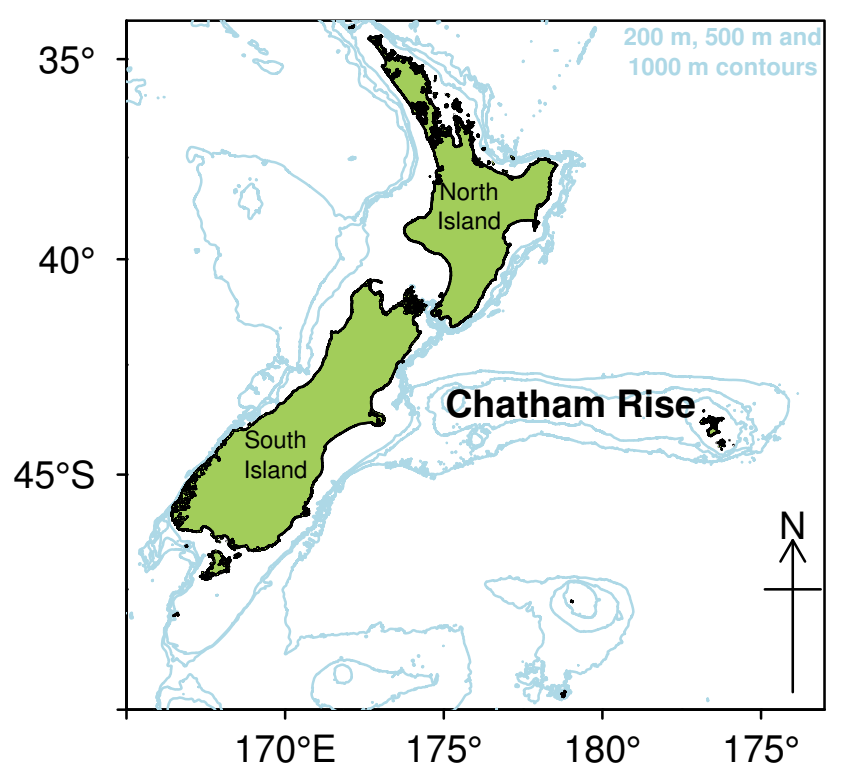

Figure 1: Map of New Zealand with Chatham Rise marked, including 200 m, $500 \mathrm{~m}$, and $1000 \mathrm{~m}$ isobaths.

Sections 3-7 cover each of these five main stages, followed by Section 8: Bringing it together, which discusses some of the implications of the models' performance, dynamics and data gaps.

\section{Model design}

An Atlantis model simulates the ecosystem through time, calculating each new state based on the previous state and the events of the current timestep. This section describes the physical, biological, ecological, and fishing components of the Chatham Rise Atlantis Model. Further details on Atlantis can be found in the Atlantis user manual (Audzijonyte et al., 2017).

\subsection{Model area}

The Chatham Rise Atlantis model area comprises waters from the shore-line around Chatham Islands (but excluding estuaries on the islands) to depths of $1300 \mathrm{~m}$ along the Chatham Rise, New Zealand (Figure 2). The western boundary of the area is defined as the $400 \mathrm{~m}$ contour on the western edge of the Mernoo Gap, a trough that separates the Chatham Rise from the 
coastal shelf off the mid east coast of South Island.

An Atlantis model requires the modelled region to be split into polygons and depth layers. Each polygon/depth layer is referred to as a cell. The intention of the splits is to capture important aspects of the region but at a simplified level such that modelling the region over many years becomes possible. If we were modelling a smaller temporal scale, we may have considered a finer spatial scale. The polygons within the modelled area are referred to as dynamic polygons, and these are surrounded by non-dynamic polygons which define the boundary conditions for the modelled domain.

Several investigations of fish communities or fish species richness indicated that the division of the Chatham Rise into polygons for Atlantis modelling should occur primarily based on depth categories, with the northern and southern slopes separated (owing to the different water masses and fish communities to the north and south of the STF), and with some longitudinal differentiation as well. Species communities were found to group in adjacent depth-defined strata, but with differences between depths on the northern and southern Rise, as well as some longitudinal differentiation (Tuck et al., 2009).

A large amount of data on the abundance and distribution of demersal fish and invertebrate species has been collected from the series of trawl surveys of depths 200-800 m on Chatham Rise in January annually from 1992 to 2014 (Livingston et al. 2002, Stevens et al. (2017)). Some of the more recent surveys in the series also included strata to depths of $1300 \mathrm{~m}$ (Stevens et al., 2017). The survey area was stratified by depth, latitude, and longitude. It was logical, therefore, to base the Atlantis model polygon boundaries on the trawl survey strata boundaries. This is also helpful for informing the model spatially based on trawl surveys. Consequently, the model area was divided into 23 dynamic polygons based on bottom depth bins $(<200 \mathrm{~m}$, 200-400 m, 400-600 m, 600-800 m, 800-1300 m), with bins deeper than $400 \mathrm{~m}$ separated into northern and southern Rise polygons, and with longitudinal separation (where trawl survey strata allowed) aimed at producing western, central, and eastern polygons. The dynamic polygon area is surrounded by 6 additional non-dynamic polygons which allows for the exchange of water, nutrients and biota into and out of the dynamic model domain. The final configuration of the dynamic and non-dynamic polygons is shown in Figure 2.

All model polygons are further divided into water column depth layers, ranging from one layer in some near-shore polygons to five layers for the deepest polygons. Depth layers are also defined in Figure 2. Each box also contains one epibenthic and one sediment layer. 

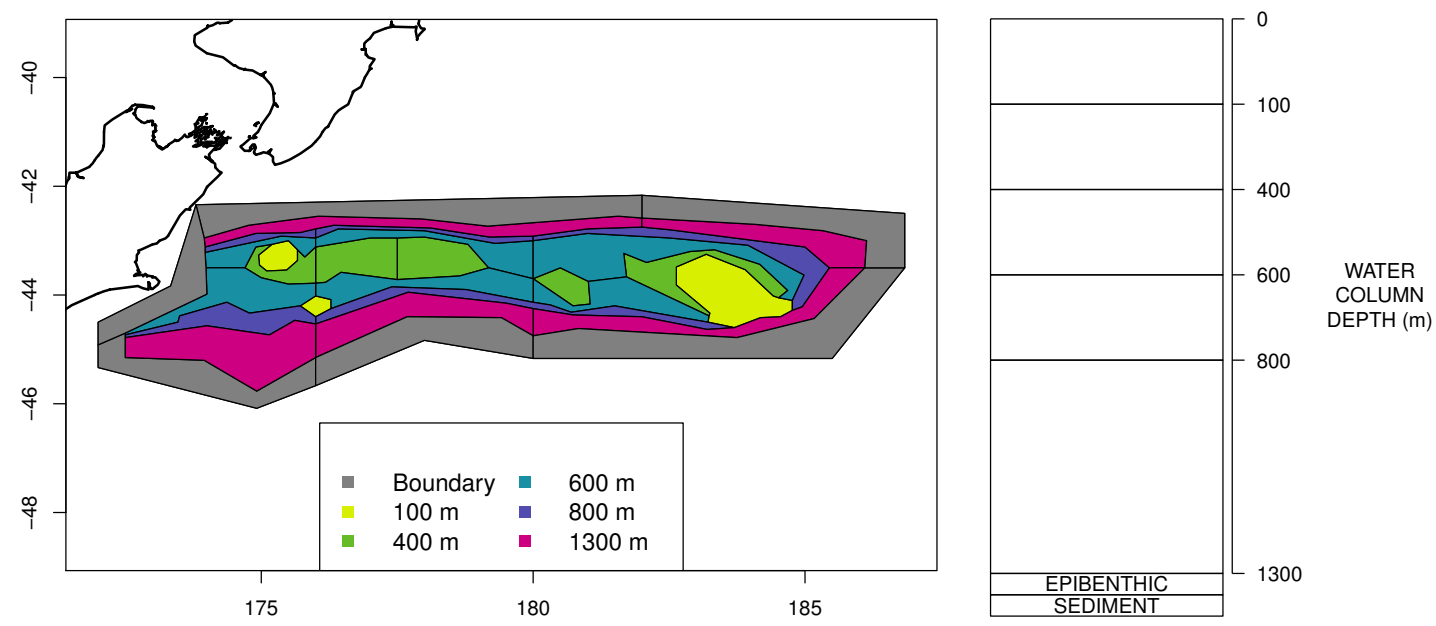

Figure 2: Polygons as defined for CRAM with maximum depths for each polygon shown by colour (left) and depth layer bins (right).

\subsection{Time}

The model was run with a 35 year burn-in period (1865-1900) followed by a 115 year modelled period (1900-2015). The burn-in period allows for the model to adjust from potentially unstable initial conditions due to uncertainty of some of the parameters and age distributions for the age resolved groups, to a state that is more stable. A 35 year period was chosen as it covered initial fluctuations of most functional groups in the model. All results presented here are from the modelled period 1900-2015. The model used 12 hour timesteps to allow for changes in temperature, light and feeding patterns between night and day.

\subsection{Oceanography}

Salinity, temperature and water exchange between cells were forced in the Atlantis model using outputs from a ROMS (Regional Oceanographic Modelling System) model (Hadfield et al., 2007) that covered years 1996-2004. Water currents across each box face cause the horizontal movement of nutrients (such as ammonia and nitrate) available to primary producers. The speed and direction of currents influence the spatial distribution of plankton groups. Water temperatures influence biological processes such as respiration (Hoegh-Guldberg and Bruno, 2010). Based on sea surface temperatures (SST), the ROMS years (1996-2004) look to be fairly representative of those properties from 1961-2017 (Figure 3). The base model presented here repeated the available ROMS variables as a nine-year cycle. Averaging the ROMS variables was not sensible due to the water exchange between cells, as these change every 12-hour timestep in strength and direction, and averaging them could easily result in implausible physical dynamics. We ran sensitivities varying the order of ROMS years or repeating one ROMS year to 
203

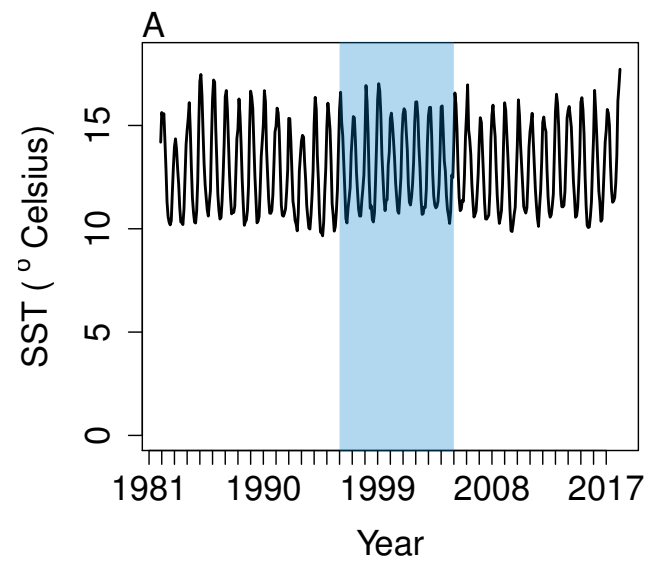

help understand the effects of inter-annual oceanographic variability on this model.

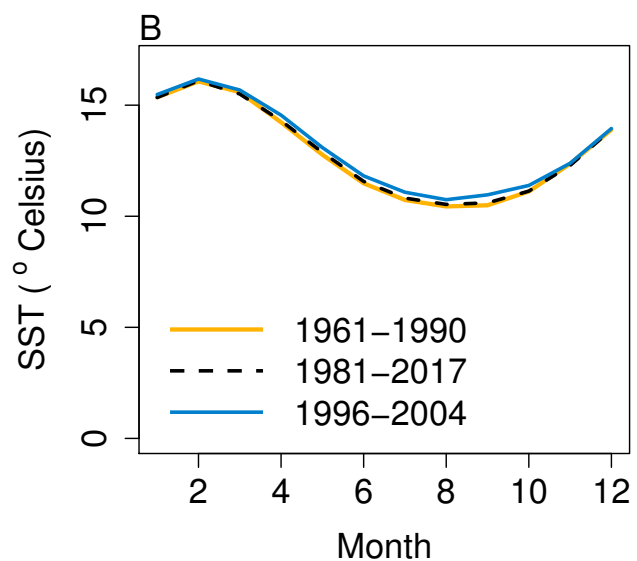

Figure 3: Sea surface temperature (SST) ( ${ }^{\circ}$ Celsius) weekly averages for 1981-2017 with ROMS years 1996-2004 shaded blue (left) and mean SST by month (right) from the same data for 1981-2017 (black dashed line), with the subset from 1996-2004 (blue solid line), and additional historical SST data from 1961-1990, which were only available as monthly averages (orange solid line).

\subsection{Nutrients}

Atlantis models use nitrogen, an important and often limiting nutrient in marine systems (Moore et al., 2013), to track the transfer of energy throughout the system. The nitrogen cycle can be seen in Figure 4. When biomass pools are tracked in the model, they are done so in $\mathrm{mg} \mathrm{N} \mathrm{m}{ }^{-3}$. When a fish (for example) eats another fish, it is nitrogen that is transferred up the food chain, with some nitrogen going to detritus and carrion, thus providing nitrogen to micro-organisms and filter feeders to fuel the cycle over again.

\subsubsection{Nutrient data}

Oxygen $\left(\mathrm{O}_{2}\right)$, nitrates $\left(\mathrm{NO}_{3}\right)$, ammonium $\left(\mathrm{NH}_{4}^{+}\right)$and silica $\left(\mathrm{SiO}_{2}\right)$ were simulated in the model, and required spatially defined initial conditions (values for each cell in the model domain). Table 1 has a summary of the data sources for these nutrients. We used values from the World Ocean Atlas (WOA) for initial conditions for nitrate values down to $500 \mathrm{~m}$, oxygen down to the full model depth of $1300 \mathrm{~m}$, and silica down to $1300 \mathrm{~m}$. The WOA contains objectively analysed climatological fields of in situ oxygen, temperature, salinity, and some nutrients (Locarnini et al., 2013; Zweng et al., 2013; Garcia et al., 2013a,b). $\mathrm{NO}_{3} \mu \mathrm{mol} / \mathrm{m}^{3}$ were converted to $\mathrm{mg} \mathrm{N} / \mathrm{m}^{3}$ by multiplying by 14 as the molecular mass of nitrogen is $14 \mathrm{~g} / \mathrm{mol}$. 


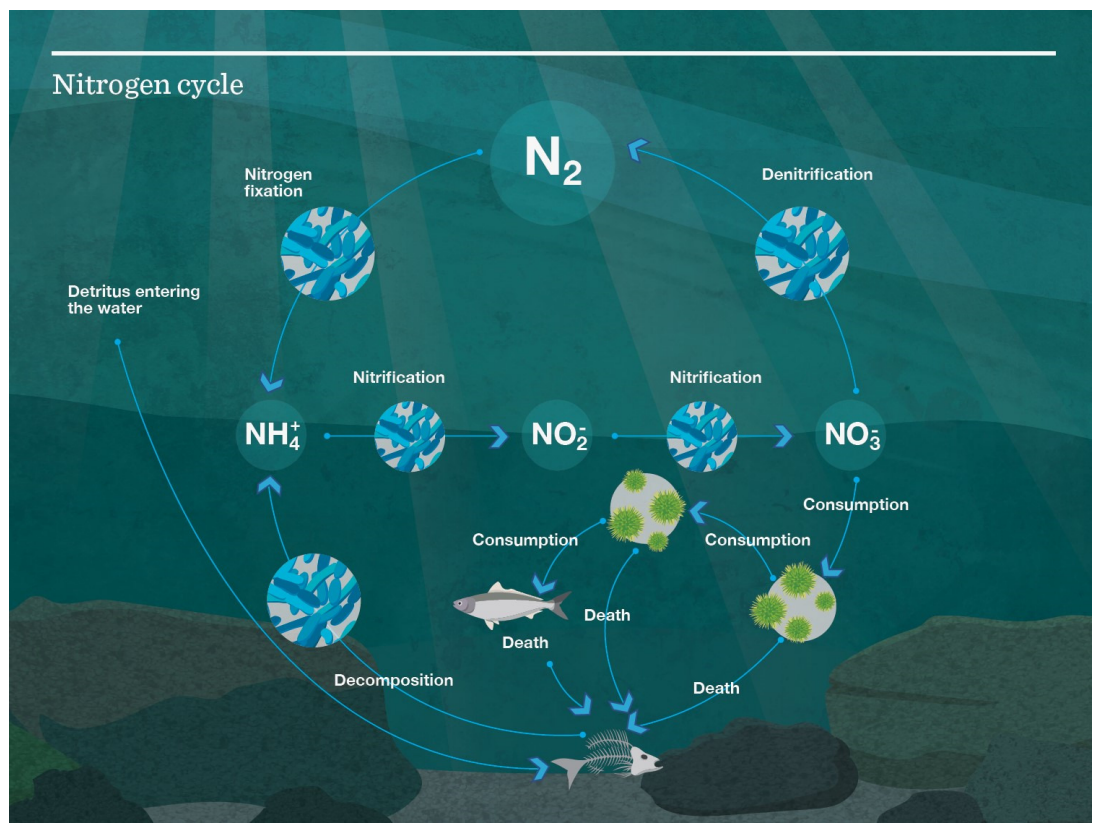

Figure 4: Nutrient cycle as modelled in Atlantis. monium is a small component of the nitrogen budget.

\subsection{Species groups}

World Ocean Circulation Experiment (WOCE) (Deutsches Ozeanographisches Datenzentrum, 2006) data were used for nitrates at depths greater than $500 \mathrm{~m}$, which were not covered by WOA. WOCE data were also used to compare values for oxygen, to inform initial conditions for silica, and to compare with salinity, temperature and chlorophyll $a$.

Ammonium values were available from NIWA (National Institute of Water and Atmospheric Research) oceanographic surveys, but only down to $50 \mathrm{~m}$. This was not too concerning as am-

Table 1: Sources of data for Oxygen, Nitrates, Ammonium and Silica. WOA, World Ocean Atlas; WOCE, World Ocean Circulation Experiment; NIWA, National Institute of Water and Atmospheric Research.

\begin{tabular}{lrrrr}
\hline Variable & Source & Depth & Latitude & Longitude \\
\hline Oxygen & WOA & $1300 \mathrm{~m}$ & $42-47 \mathrm{~S}$ & $172 \mathrm{E}-170 \mathrm{~W}$ \\
Oxygen & WOCE & $1300 \mathrm{~m}$ & $42.5 \mathrm{~S}$ & $180 \mathrm{E}$ \\
Nitrate & WOA & $500 \mathrm{~m}$ & $42-47 \mathrm{~S}$ & $172 \mathrm{E}-170 \mathrm{~W}$ \\
Nitrate & WOCE & $1300 \mathrm{~m}$ & $42.5 \mathrm{~S}$ & $180 \mathrm{E}$ \\
Silica & WOCE & $1300 \mathrm{~m}$ & $42.5 \mathrm{~S}$ & $180 \mathrm{E}$ \\
Ammonium & NIWA survey & $0-50 \mathrm{~m}$ & $43-46 \mathrm{~S}$ & $172 \mathrm{E}-180 \mathrm{E}$ \\
\hline
\end{tabular}

CRAM uses 53 functional groups to model the biological processes. Of these 53 groups, 15 vertebrates, and one invertebrate comprised single species; all other groups comprised two or more species. The main component species of the groups are shown in Tables 2 -5 . All vertebrate groups and five invertebrate groups were modelled with age-structure using up to 10 age-classes and varying number of years per age-class, depending on 
Table 2: List of functional vertebrate groups for CRAM. Name is the species group name which is the same as the main species name for single-species groups but without punctuation. Lifespan is the assumed maximum number of years an individual in that group may live. Ben, benthic; Dem, demersal; invert, invertivore; pisc, piscivore.

\begin{tabular}{|c|c|c|}
\hline Name & Main species & Lifespan (years) \\
\hline Baleen whales & Southern right whales (Eubalaena australis) & 80 \\
\hline Basketwork eel & Basketwork eels (Diastobranchus capensis) & 30 \\
\hline Baxters dogfish & Baxter's dogfish (Etmopterus baxteri) & 50 \\
\hline Ben fish deep & Four-rayed rattail (Coryphaenoides subserrulatus) & 20 \\
\hline Ben fish shal & Oblique banded rattail (Coelorinchus aspercephalus) & 10 \\
\hline Black oreo & Black oreo (Allocyttus niger) & 120 \\
\hline Bollons rattail & Bollons' rattail (Caelorinchus bollonsi) & 20 \\
\hline Cetacean other & Primarily sperm \& pilot whales \& dolphins & 30 \\
\hline Dem fish pisc & Giant stargazer (Kathetostoma giganteum) & 20 \\
\hline Elasmobranch invert & Primarily skates \& dogfish & 20 \\
\hline Elasmobranch pisc & Primarily semi-pelagic sharks & 50 \\
\hline Epiben fish deep & Spiky oreo (Neocyttus rhomboidalis) & 100 \\
\hline Epiben fish shal & Common roughy (Hoplostethus atlanticus) & 10 \\
\hline Ghost shark & Dark ghost shark (Hydrolagus novaezealandiae) & 20 \\
\hline Hake & Hake (Merlucciidae) & 30 \\
\hline Hoki & Hoki (Macruronus novaezelandiae & 20 \\
\hline Javelinfish & Javelinfish (Coelorinchus australis) & 10 \\
\hline Ling & Ling (Molva molva) & 30 \\
\hline Lookdown dory & Lookdown dory (Cyttus traversi) & 30 \\
\hline Mackerels & Slender jack mackerel (Trachurus murphyi) & 30 \\
\hline Orange roughy & Orange roughy (Hoplostethus atlanticus) & 120 \\
\hline Pelagic fish lge & Southern bluefin tuna (Thunnus thynnus) & 20 \\
\hline Pelagic fish med & Barracouta ( Thyrsites atun) & 10 \\
\hline Pelagic fish sml & Myctophids (Myctophidae) & 4 \\
\hline Pinniped & NZ fur seal (Arctocephalus forsteri) & 20 \\
\hline Reef fish & Blue cod (Parapercis colias) & 20 \\
\hline Seabird & Seabirds \& shorebirds & 20 \\
\hline Seaperch & Seaperch (Helicolenus spp.) & 50 \\
\hline Shovelnosed dogfish & Shovelnosed dogfish (Deania calcea) & 40 \\
\hline Smooth oreo & Smooth oreo (Pseudocyttus maculatus) & 100 \\
\hline Spiny dogfish & Spiny dogfish (Squalus acanthias) & 30 \\
\hline Warehou & Silver, white \& blue warehou & 20 \\
\hline
\end{tabular}


Table 3: List of functional invertebrate groups for CRAM. Name is the species group name which is the same as the species name for singlespecies groups. Description includes main species. Lifespan is the maximum number of years an individual in that group may live. Those groups with no value for lifespan are modelled as biomass pools and hence do not have a lifespan defined as this is only relevant when modelling numbers. Zoo, zooplankton; Invert comm, commercial invertebrates; herb, herbivore; scav, scavenger.

\section{Name}

Arrow squid

Benthic Carniv

Carniv Zoo

Cephalopod other

Deposit Feeder

DinoFlag

Filter Other

Gelat Zoo

Invert comm herb

Invert comm scav

Meiobenth

MesoZoo

MicroZoo

Rock lobster

\section{Description}

Arrow squid

Benthic carnivores

Planktonic animals (size 2-20 cm)

Squid \& octopus

Detritivores and benthic grazers

Dinoflagellates

Non-commercial benthic filter feeders

Salps, ctenophores, jellyfish

Paua \& kina

Primarily scampi \& crabs

Benthic organisms (size $0.1-1 \mathrm{~mm}$ )

Planktonic animals (size $0.2-20 \mathrm{~mm}$ )

Heterotrophic plankton (size 20-200 $\mu \mathrm{m}$ )

Rock lobster
Lifespan (years)

2

2

10

14

12

Table 4: List of functional phytoplankton and algae groups for CRAM. Name is the species group name which is the same as the main species name for single-species groups. Description includes main species.

$\begin{array}{ll}\text { Name } & \text { Description } \\ \text { Diatoms } & \text { Diatoms (large phytoplankton) } \\ \text { Macroalgae } & \text { Macroalgae } \\ \text { Microphytobenthos } & \text { Unicellular benthic algae } \\ \text { Pico-phytoplankton } & \text { Small phytoplankton }\end{array}$

Table 5: List of functional bacteria and detritus groups for CRAM. Name is the species group name which is the same as the main species name for single-species groups. Description includes main species.

$\begin{array}{ll}\text { Name } & \text { Description } \\ \text { Carrion } & \text { Dead and decaying flesh } \\ \text { Labile detritus } & \text { Organic matter that decomposes at a fast rate } \\ \text { Pelagic bacteria } & \text { Pelagic bacteria } \\ \text { Refractory detritus } & \text { Organic matter that decomposes at a slow rate } \\ \text { Sediment bacteria } & \text { Sediment bacteria }\end{array}$




\subsubsection{Initial conditions and biological parameters for species groups}

Initial biomasses for each species group were estimated using a single species stochastic stock assessment model, CASAL (Bull et al., 2012). Biomass estimates for the entire Chatham Rise were derived by using known biological parameters and a catch history to project back from an absolute abundance estimate in 2003. Values of relative abundance were available for most species groups from trawl surveys conducted annually from 1992 to 2014 (see O'Driscoll et al. (2011)). For each survey, these abundance estimates were converted to absolute values using trawl catchability quotients (specific to each group) derived by our expert opinion, as fisheries scientists with experience dating back more than 30 years. Estimated absolute abundance for each group in 2003 (the midpoint of the survey series) was taken as the mean from all the survey estimates. For each species group, the initial biomass estimate was distributed across polygons in proportion to the survey series estimates (i.e., the mean proportion of total biomass by polygon over the survey series). The distribution of biomass by depth layer in each polygon was derived using our expert opinion. Where there was no available catch history (e.g. seabirds), or no useful estimates of relative abundance from the trawl surveys (e.g. rock lobster), initial biomasses (and their distribution by model polygon) were estimated using our expert opinion. For age-structured groups, initial biomass estimates were assigned to age-classes using estimates of instantaneous natural mortality $(M)$. Initial average weights at age were calculated using Von Bertalanffy growth and length-weight conversion parameters. Values used for these parameters are in Table 6. Weights at age were split into reserve and structural components using ratio $R_{N}: S_{N}=2.5: 1$. This allows for an individual's body mass to decrease by approximately $70 \%$ before starving, which is within the $60-80 \%$ range suggested by Broekhuizen et al. (1994).

All age-structured groups were modelled with Beverton-Holt recruitment, the steepness $(h)$ values for which are in Table 6 . These values are not ever well known, and scenarios explored using this model should consider sensitivities for these.

Table 6: Biological parameters assumed for age-structured species groups. VB, von Bertalanffy; M, instantaneous natural mortality rate; $\mathrm{h}$, steepness value for the Beverton-Holt stock recruitment relationship. Length-weight parameters are: $W=a L^{b}$ (weight $W$ in g, length $L$ in $\mathrm{cm})$. Where Reference is 'Trawl db' some data have been derived from the NIWA trawl survey database (see Mackay (2000)). Species group matches 'Name' in Tables 2 and 3 and are without punctuation.

\section{Species group} VB Growth Length-weight 
Arrow squid

Baleen whales

Basketwork eel

Baxters dogfish

Ben fish deep

Ben fish shal

Black oreo

Bollons rattail

Cephalopod other

Cetacean other

Dem fish pisc

Elasmobranch invert

Elasmobranch pisc

Epiben fish deep

Epiben fish shal

Ghost shark

Hake

Hoki

Invert comm herb

Invert comm scav

Javelinfish

Ling

Lookdown dory

Mackerels

Orange roughy

Pelagic fish lge

Pelagic fish med

Pelagic fish sml

Pinniped $\begin{array}{lllll}\text { Linf (cm) } & \text { K } & T_{0} & a & b\end{array}$

$\begin{array}{lllll}35 & 2.4 & 0 & 2.90 \mathrm{E}-02 & 3\end{array}$

64

36

38

0

37

47.3

45

0.283

2.4

$-1.29$

2.35E-03

$0 \quad 2.90 \mathrm{E}-02$

69.8

0.17

$-0.53-1.50 \mathrm{E}-02$

150.

150.5

84.

35.

0.1065

0.095

$-1.06$

$2.68 \mathrm{E}-02$

$-4.56 \quad 1.50 \mathrm{E}-03$

2.93

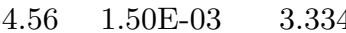

$-0.5 \quad 2.83 \mathrm{E}-02 \quad 2.9322$

0.07

(1)

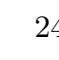

97

95.9

100.8

0.18

$-0$.

0.09

$-1.1$

0.279

0.164

0.0

$-2.1$

.16

$2.00 \mathrm{E}-03$

155

50

51

135.2

5

$50 \quad 0.075$

0.15
0.25
0.216
0.105
0.075$$
0
$$

0

$3.73 \mathrm{E}-04$

$1.38 \mathrm{E}-03$

$-0.72 \quad 1.07 \mathrm{E}-03$

-1 2.35E-02

3.303

3.145

3.13

3.336

2.97

74.25

37.2$$
18
$$

82

0.11

0.11

0.065

$-0$.

0.205

85

85.2

7

0.8

1.30E-02

2.81

2.94

$0.07 \quad 0.5$
0.3

0.7

1.58

0.7

Ministry for Primary Industries (2016)

$0.01 \quad 0.5$

8 Trawl db

0.3 Irvine et al. (2006a)

0.8 Stevens et al. (2010), Trawl $\mathrm{db}$

Stevens et al. (2010), Trawl $\mathrm{db}$

Ministry for Primary Industries (2016)

Stevens et al. (2010)

Sutton (1999), Ministry for Primary Industries (2016)

Ministry for Primary Industries (2016)

Irvine et al. (2006b)

Stewart and Smith (1994), Trawl db

Trawl db

Ministry for Primary Industries (2016)

Horn (2013)

McKenzie (2016), Ministry for Primary Industries (2016)

$0.15 \quad 0.8 \quad$ Breen et al. (2003)

$0.2 \quad 0.8$ Tuck (2016)

$0.35 \quad 0.8 \quad$ Stevens et al. (2010)

$0.14 \quad 0.84 \quad$ McGregor (2015)

0.15 0.8 Stewart and Smith (1994), Ministry for Primary Industries (2016)

Cubillos et al. (1998), Kochkin (1994)

Ministry for Primary Industries (2016)

Fournier et al. (1990), Ministry for Primary Industries (2016)

Horn (2002), Ministry for Primary Industries (2016)

Young et al. (1988), Trawl $\mathrm{db}$ 


\begin{tabular}{|c|c|c|c|c|c|c|c|c|}
\hline Reef fish & 51.7 & 0.087 & -1.7 & $1.91 \mathrm{E}-02$ & 2.9818 & 0.14 & 0.8 & $\begin{array}{l}\text { Ministry for Primary Indus- } \\
\text { tries }(2016)\end{array}$ \\
\hline Rock lobster & 85 & 0.15 & 0 & $4.16 \mathrm{E}-03$ & 2.935 & 0.12 & 0.8 & $\begin{array}{l}\text { Ministry for Primary Indus- } \\
\text { tries (2017) }\end{array}$ \\
\hline Seabird & & & & & & 0.11 & 0.5 & \\
\hline Seaperch & 45.6 & 0.08 & -0.8 & $7.77 \mathrm{E}-03$ & 3.22 & 0.07 & 0.8 & $\begin{array}{l}\text { Paul and Horn (2009), Min- } \\
\text { istry for Primary Industries } \\
(2016)\end{array}$ \\
\hline Shovelnosed dogfish & 106.4 & 0.106 & -0.384 & $1.58 \mathrm{E}-03$ & 3.192 & 0.13 & 0.3 & $\begin{array}{l}\text { Clarke et al. (2002), Trawl } \\
\text { db }\end{array}$ \\
\hline Smooth oreo & 46 & 0.07 & -1.5 & $3.05 \mathrm{E}-02$ & 2.885 & 0.063 & 0.75 & $\begin{array}{l}\text { Ministry for Primary Indus- } \\
\text { tries }(2016)\end{array}$ \\
\hline Spiny dogfish & 104.8 & 0.093 & -3.17 & $1.30 \mathrm{E}-03$ & 3.2639 & 0.2 & 0.3 & $\begin{array}{l}\text { Hanchet (1986), Beentjes } \\
\text { and Stevenson (2009) }\end{array}$ \\
\hline Warehou & 53.1 & 0.37 & -0.88 & $8.28 \mathrm{E}-03$ & 3.214 & 0.25 & 0.8 & $\begin{array}{l}\text { Horn and Sutton (1996), } \\
\text { Ministry for Primary Indus- } \\
\text { tries (2016) }\end{array}$ \\
\hline
\end{tabular}

\subsection{Predation}

Simulated predation was a four step process that occurred within each cell and at each timestep. From the predator's perspective the steps modelled can be summarised as: 1.) Am I allowed to eat it? 2.) Is it in the same place at the same time as me? 3.) Does it fit in my mouth? 4.) How much can I eat? Full details are in the Atlantis User's Guide (Audzijonyte et al., 2017). Step 4 uses a feeding functional response, of which there are 12 options currently available in Atlantis. We have applied the Holling Type II functional response to all age-structured species groups in this model, thus influencing the amount of prey consumed by prey abundance, and the predators search rate and handling time.

Diets of each species group were summarised in categories Algae, Bacteria, Bird, Cetacea, Coelenterate, Crustacean, Detritus, Echinoderm, Elasmobranch, Microzooplankton, Mollusc, Phytoplankton, Polychaete, Teleost, and Tunicate similar to that done in the diet study of Stevens et al. (2011a) (Figure 5). While this summary misses the temporal, spatial, age and size components of the predator-prey interactions, it is useful to check overall diets. For example, warehou and smooth oreos eat mostly salps (tunicates) as expected; Baxter's dogfish eat mostly fish, crustaceans, molluscs and tunicates as expected; and invertebrate herbivores (kina and paua) eat mostly algae, although they should also eat some phytoplankton, which they do but it is lost in the detail. 


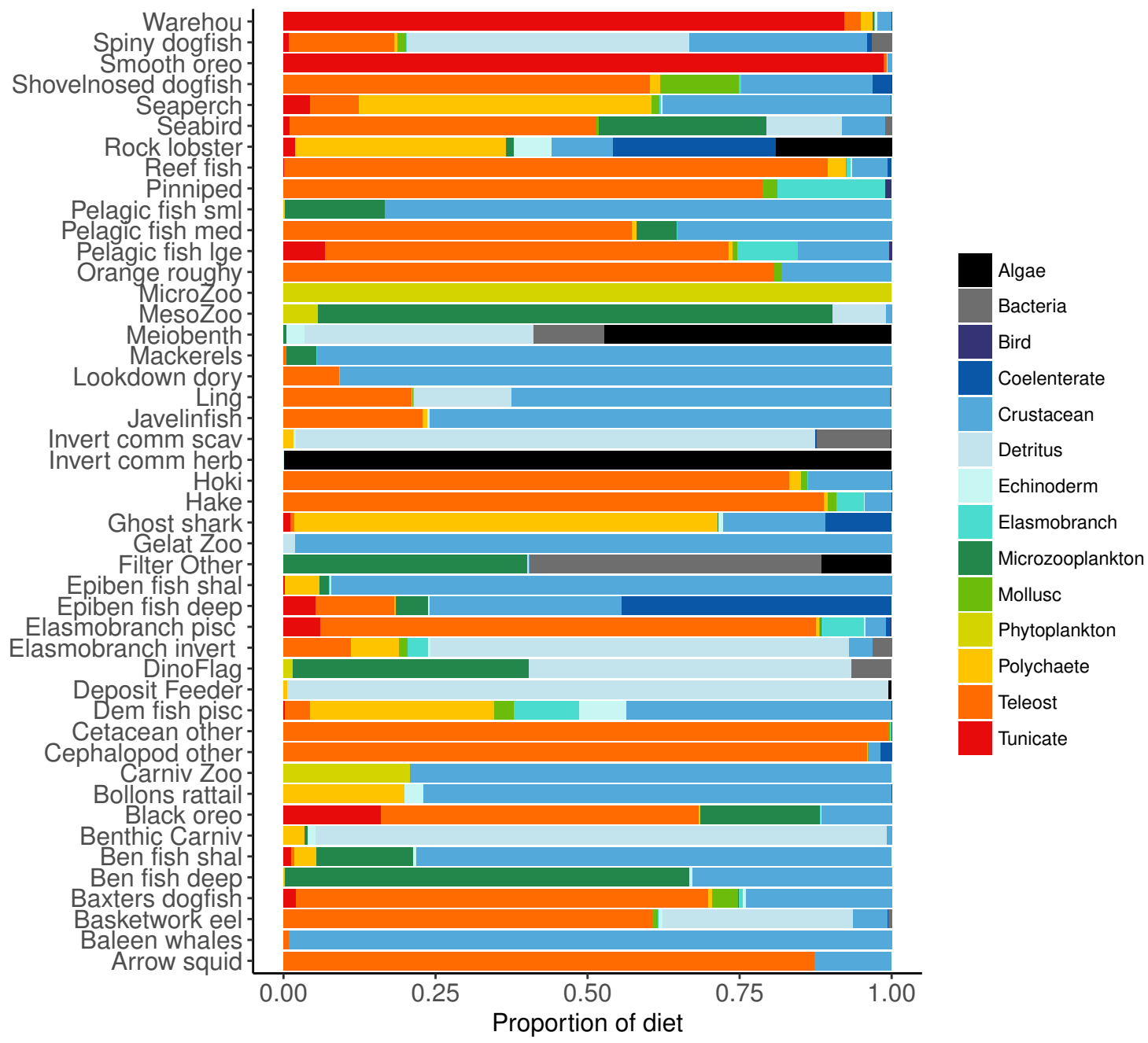

Figure 5: Summary of the proportion of prey groups in the diets of species functional groups

(Tables 2 and 3) over model years 1900-2016 from the fished model where the proportion is by $\mathrm{mg}$ $\mathrm{N}$ consumed. 


\section{Calibration}

Calibration of the model included ensuring stable biomass trajectories when applying no fishing; realistic realised diets; realistic growth and mortality (size-at-age and proportions-at-age); and biomass decreasing with increasing trophic level following the PREBAL (Link, 2010) guidelines.

Biomass trajectories should reach a quasi-equilibrium when modelled with constant oceanography and no fishing (Kaplan and Marshall, 2016). While oceanography is not constant in our non-fishing model as it changes by year (Section 3.3), most of the agestructured groups should still be fairly stable. This was generally the case; all biomass trajectories remained within CVs of 20\% over the simulated 1900-2016 model period, except for invertebrate scavengers (commercial) and seaperch. Invertebrate scavengers (commercial) are primarily scampi, and they are likely responding to changes resulting from the oceanographic variables. Biomass trajectories for all age-structured groups from the un-fished model are in Appendix A. Seaperch biomass was trending downward initially, but they seem to have reached an equilibrium by about 1950, with expected growth and mortality rates.

Atlantis simulates growth rates of age-structured groups as a function of consumption. If growth is too slow, there may be insufficient food available, the feeding search rate could be too low or handling time too high, and the reverse of these when growth is too fast. Simulated growth rates of age-structured species groups were assessed by comparing the simulated size-at-age with those expected based on growth curve estimates from the literature (Table 6). The overlaid simulated and 'observed' figures were generally very similar (Appendix B). For each species group, we estimated CVs required to satisfy the hypothesis that the modelled size-at-age were not significantly different from the 'observed' with probability of 0.95 . The required CVs were all less than $30 \%$ except for epibenthic fish (deep and shallow), invertebrate herbivore (commercial), invertebrate scavenger (commercial), ling, rock lobster and small pelagic fishes. For all these groups, the first age class, and sometimes the first few, were larger in size than expected. Deep epibenthic fish were larger than expected at all age classes, but for all other groups the characteristic of larger than expected size at age had been remedied by the time they were adults.

Natural mortality in the model consists of mortality intrinsic within the model from predation, starvation, and light, oxygen or nutrient deprivation, and additional forced 


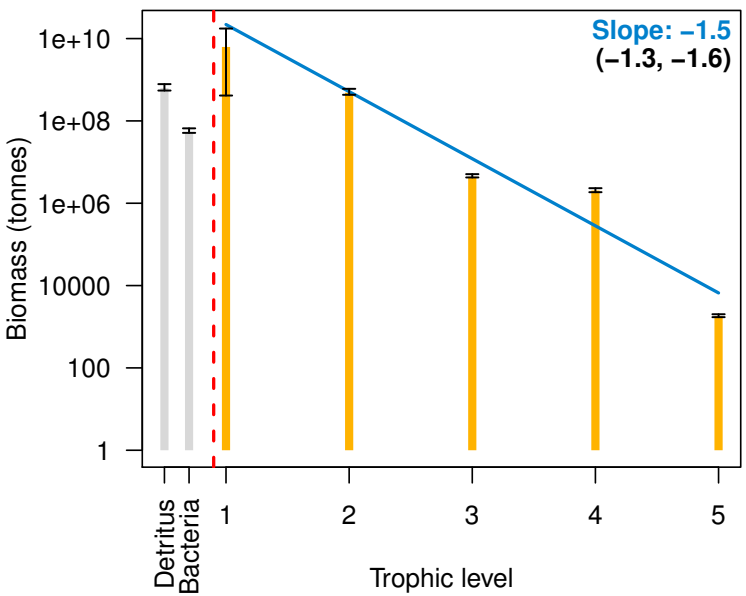
less mortality. as a level 3 .

mortality. The latter was applied for modelled species groups that would not otherwise suffer sufficient natural mortality within the model, such as those that have little known predation. Age-structured simulated natural mortality rates from the stable base model were compared to estimates of $M$ from the literature where available (Table 6 ) by comparing the proportions-at-age. The overlaid simulated and 'observed' figures were generally very similar (Appendix C), although rock lobster and invertebrate herbivore commercial (primarily paua and kina) had slightly more mortality in the model, and demersal piscivores, epibenthic fish small, pelagic fish medium, and warehou had slightly

We summarised biomass by trophic level for the base model as at 2016 on a log-scale, and biomass reduced with increasing trophic level with a fitted slope of -1.6 (Figure 6). This was close to the recommended range of PREBAL of $(-1.5,-0.5)$. The biomass at trophic level 4 was slightly higher in this summary than in the model, as the summary was based on adult trophic level and many of the fish species are trophic level 4 as adults, but lower as juveniles. This resulted in the biomass of the juveniles for these fish adding to the level 4 biomass whereas in the model they were perhaps functioning

Figure 6: Biomass by trophic level with 95\% confidence intervals from the 1900-2016 Chatham Rise Atlantis model simulation. The blue line is the fitted linear model to the median biomasses by trophic level, the slope which is in blue. The slopes of the linear models to fitted to the upper and lower $95 \%$ confidence interval limits are given in brackets. 


\section{Sensitivity analyses}

\subsection{Oceanography}

Oceanographic variables from a ROMS (Regional Oceanographic Modelling System) model for years 1996-2004 were used to define temperature, salinity and flux (water exchange). As our model spanned more than these years, we needed to recycle the ROMS variables in some way. The purpose of this section has two parts: 1.) establishing confidence intervals for our model simulations with respect to oceanographic variability; 2.) assessing the effect of repeating oceanographic variables from any one year, and whether these take the model outside of the established confidence intervals.

To retain realistic within-year dynamics, the ROMS variables from each year were kept together as a unit, and the years covered by the ROMS model were considered the samples. We ran two sets of simulations: the first sampled ROMS years at random with replacement for each model year simulated (bootstrapped the ROMS years) and repeated this for 50 model runs; the second repeated one ROMS year for all model years simulated and did a separate model run for each of the nine ROMS years. In both cases, the 2003 ROMS was repeated for a 35-year burn-in period, followed by a 50 year simulation. The 2003 ROMS was chosen for the burn-in period as this year had the closest sea temperatures to the means from all ROMS years (Figure 7). Bootstrapping the ROMS years was used to establish confidence intervals with respect to between-year oceanographic variability. Repeating each ROMS year in turn was testing the effect of multiple years being different to the other years in some consistent way, such as cooler or warmer.

The established biomass confidence intervals were fairly narrow for most species groups, with $\mathrm{CVs}<10 \%$. Of the exceptions, diatoms had the highest $\mathrm{CV}$ of $79 \%$, followed by carnivorous zooplankton (46\%), labile detritus (23\%), sediment bacteria $(13 \%)$, invertebrate scavengers (commercial) $(12 \%)$, refractory detritus (12\%), mesozooplankton (11\%) and pelagic bacteria (11\%). That these groups were found to be most sensitive to oceanographic variability in the model is a plausible and sensible result.

The years with cooler sea temperatures (1996, 1997, and 2004) when repeated for 50 years produced the most species groups that went above the established biomass confidence intervals, with the on average warmer years (1999, 2000, and 2001) having the most species groups that went below (Figure 8). These species groups affected by 

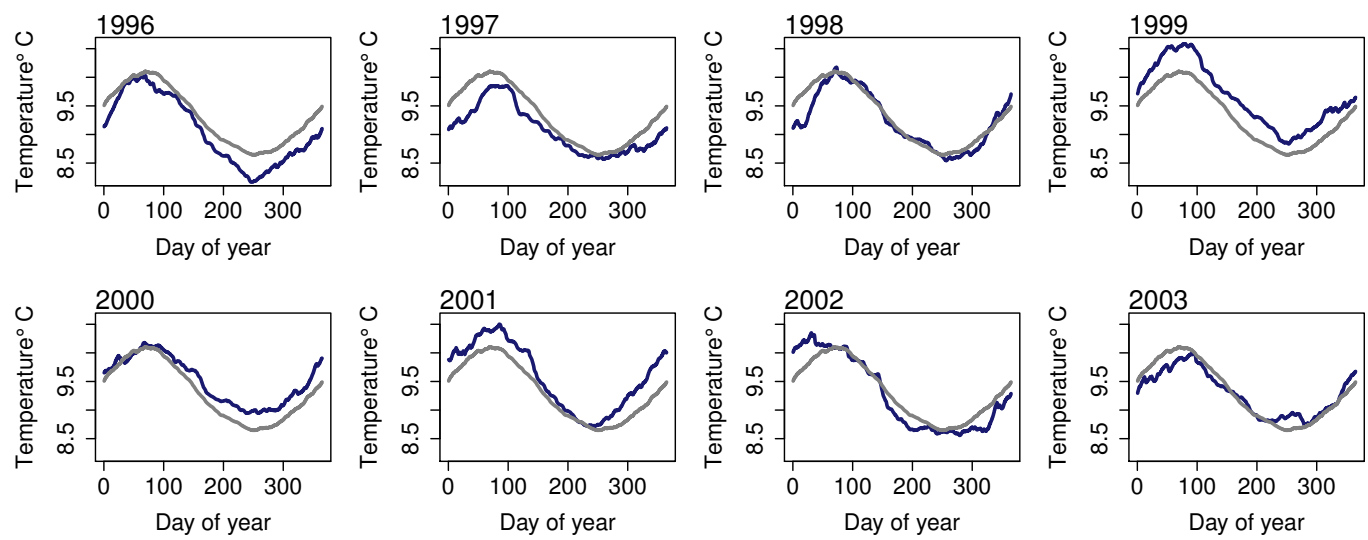
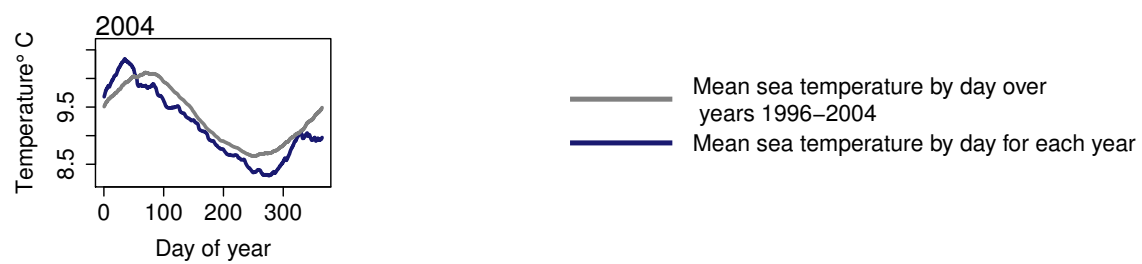

Figure 7: Sea temperature $\left({ }^{\circ} \mathrm{C}\right)$ from ROMS model outputs by day for each year 1996-2004 (dark blue line) and median sea temperature over all ROMS model years 1996-2004 (grey line).

\subsection{Connectivity and influence}

Understanding which species groups are most influential or responsive in the model is another test for realistic dynamics, and may be useful to help understand results of scenarios explored using this model in the future. To do this, we need to perturb each species group in turn, then assess the responses of the other groups in the system. For each age-structured species group, we ran two simulations, one with a small additional 


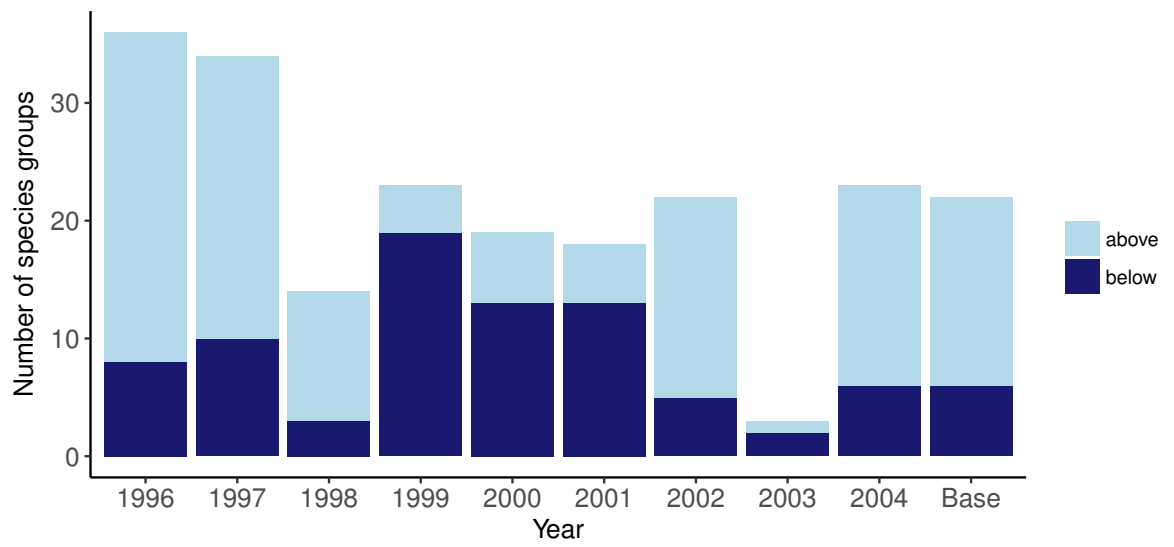

Figure 8: Number of species groups for each simulation with one ROMS year repeated that went above (light blue) or below (midnight blue) the limits of bootstrapped ROMS simulations and for the Base Model where the years were repeated in order for the entire model simulation.

mortality and one larger; $M$ (per year) $+(0.1,0.005)$. We assessed responses of the groups with respect to the Base Model at the completion of 50-year simulations. We analysed the 'keystoneness' and responsiveness of the groups based on biomasses relative to the Base Model.

We calculated keystoneness using an adaption of the method in Libralato et al. (2006). It is a measure of the effect the group has on the rest of the system (change in biomass of the other species groups), that takes into account its proportion of the total biomass. For example, if two species groups have the same effect, but one has a large biomass and one a small biomass, the smaller would have a larger keystoneness. We used simulation outputs to estimate the total effect $(\epsilon)$ of each species group (Equation 1) which used the change in biomass of each group relative to the Base Model (Equation $2)$. The simulated change in biomasses $\left(S_{f, g}\right)$ were used in place of the mixed trophic impact values calculated from mass balanced models and used by Libralato et al. (2006). As the additional mortality applied in our simulations caused larger and smaller changes to the focus groups, we scaled the focus groups' biomass proportions by their change in biomass $\left(S_{f, f}\right.$ in Equation 4$)$. Hence, the resulting keystoneness allowed for the effect changing each group had on the other groups, the focus groups biomass as a proportion of the total, and the proportional change in biomass of the focus group relative to the base model. 


$$
\begin{gathered}
\epsilon_{f}=\sqrt{\sum_{g \neq f}^{G} S_{f, g}^{2}} \\
S_{f, g}=\frac{B_{f, g}-B_{b, g}}{B_{b, g}} \\
\kappa_{f}=\log \left(\epsilon_{f}\left(1-p_{f}\right)\right) \\
p_{f}=\frac{B_{b, f}}{\sum_{g=1}^{G} B_{b, g}} \times\left|S_{f, f}\right|
\end{gathered}
$$

$\epsilon_{f}$, effect group $f$ has on the other groups

$S_{f, g}$, proportional change in biomass of group $g$ when group $f$ was reduced, relative to the Base Model

$B_{b_{g}}, B_{b_{f}}$, biomass in base model of group $g, f$

$B_{f_{g}}$, biomass of group $g$ in model with group $f$ mortality increased

$\kappa_{f}$, keystoneness of group $f$

$p_{f}$, biomass proportion of group $f$

There were four species groups that stood out as having more effect than the other groups: orange roughy, hoki, pelagic fish small (primarily myctophids) and spiny dogfish. These remain the top four for keystoneness, but the order changes due to the proportional biomasses (Figure 9).

We calculated responsiveness in a similar way to keystoneness, but from the perspective of the response group (Equation 5).

$$
R_{g}=\sqrt{\sum_{f \neq g}^{G}\left(m_{f, g}^{2} \times p_{f}\right)}
$$

$R_{g}$ responsiveness of group $g$ to increased mortality in all other groups

The most responsive group was pelagic fish small (primarily myctophids), followed by smooth oreo, invertebrate scavengers commercial (primary scampi), and pelagic fish medium (primarily barracouta) (Figure 10). The pelagic fish small species group ranked high for keystoneness and responsiveness, and so may be most important and influential in scenarios explored with this model. 


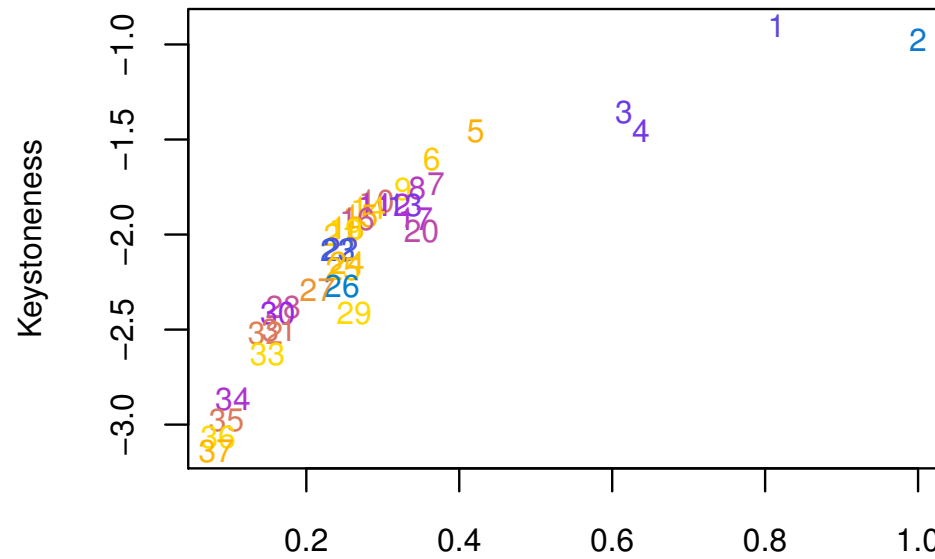

\author{
Biomass proportion \\ 1e-04 \\ 0.001 \\ 0.01 \\ 0.1
}

Relative overall effect

1 Hoki
2 Orange roughy
3 Spiny dogfish
4 Pelagic fish sml
5 Ben fish shal
6 Seabird
7 Pelagic fish med
8 Epiben fish shal
9 Cetacean other
10 Hake
11 Ling
12 Shovelnosed dogfish
13 Warehou

27 Javelinfish 28 Baxters dogfish 29 Pelagic fish Ige 30 Ghost shark 31 Dem fish pisc 32 Elasmobranch invert 33 Invert comm scav 34 Seaperch 35 Ben fish deep 36 Pinniped 37 Rock lobster

Figure 9: Keystoneness (y-axis) and relative overall effect (x-axis) for all age-structured species groups, with numbers giving keystoneness ranking (1 is the most influential using Equation 3). Colours indicate biomass proportion scaled by proportional change in biomass (Equation 4).

\title{
6 Fishing
}

Most of the fisheries on the Chatham Rise became established after the mid-1970's, with the exception of the blue cod (Parapercis colias) (reef fish species group) fishery which extends back to the early 1900's. Individual catch histories are in Appendix D and Figure 11 presents a summary of catches from the Chatham Rise with the top six species by total catch shown in colour and the others combined into an 'other' category. Hoki had the largest total catch, followed by orange roughy, smooth oreo, ling, black oreo, then barracouta. Orange roughy comprised the largest individual fishery in the late-1970's-early-1990's after which it declined markedly; from the 1990's hoki was the 


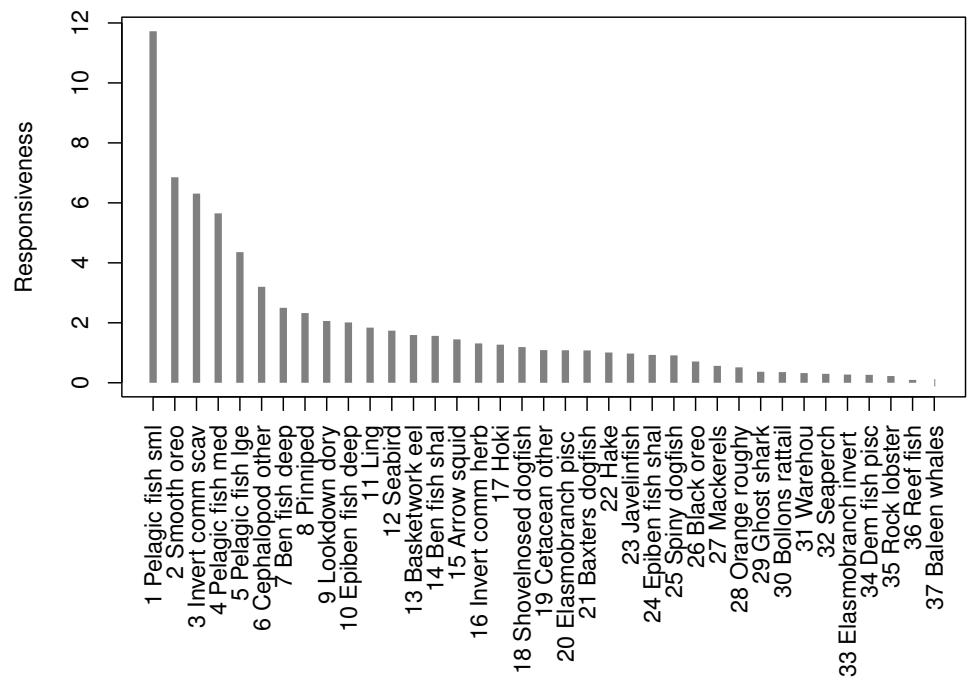

Figure 10: Responsiveness of age-structured species groups after 50 years of perturbation, as calculated in Equation 5.

dominant fishery.

The fisheries were modelled with six fleets, defined in Table 7. The demersal line fishery was dominant until mid-late 1960's when the demersal trawl fishery became dominant, catching approximately 70000 tonnes per year (Figure 12). The historical catches from these fleets were forced in the model using spatially and temporally resolved inputs.

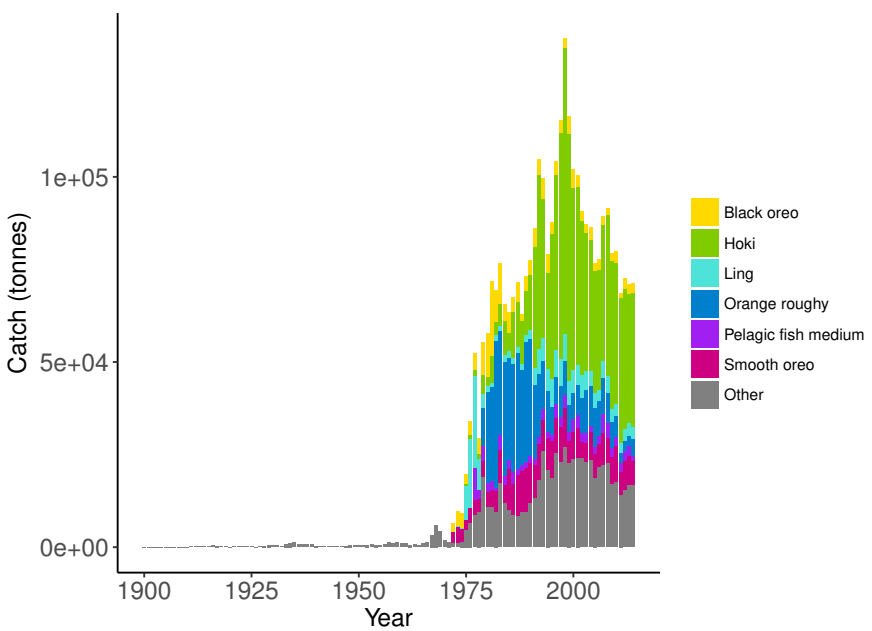

Figure 11: Tonnes caught from Chatham Rise 1900-2014 for all species with top six species groups by total catch coloured separately. 
Table 7: Fishing fleets defined for Chatham Rise Atlantis model. Number of species groups is the number of species groups that have been caught by each fishing fleet; total catch is the total tonnes caught by each fishing fleet from 1900-2014.

\section{Code}

trawlDEM

lineDEM

snetDEM

potIVS

jigCEP

diveIVH

\section{Description}

trawl on demersals and mesopelagics line on demersals and mesopelagics setnet on demersals and sharks potting on lobster and blue cod

jig on squid

diving on paua and kina
Number of species groups Total catch (t)

2850000

1200000

45700

241000

1700

158000 


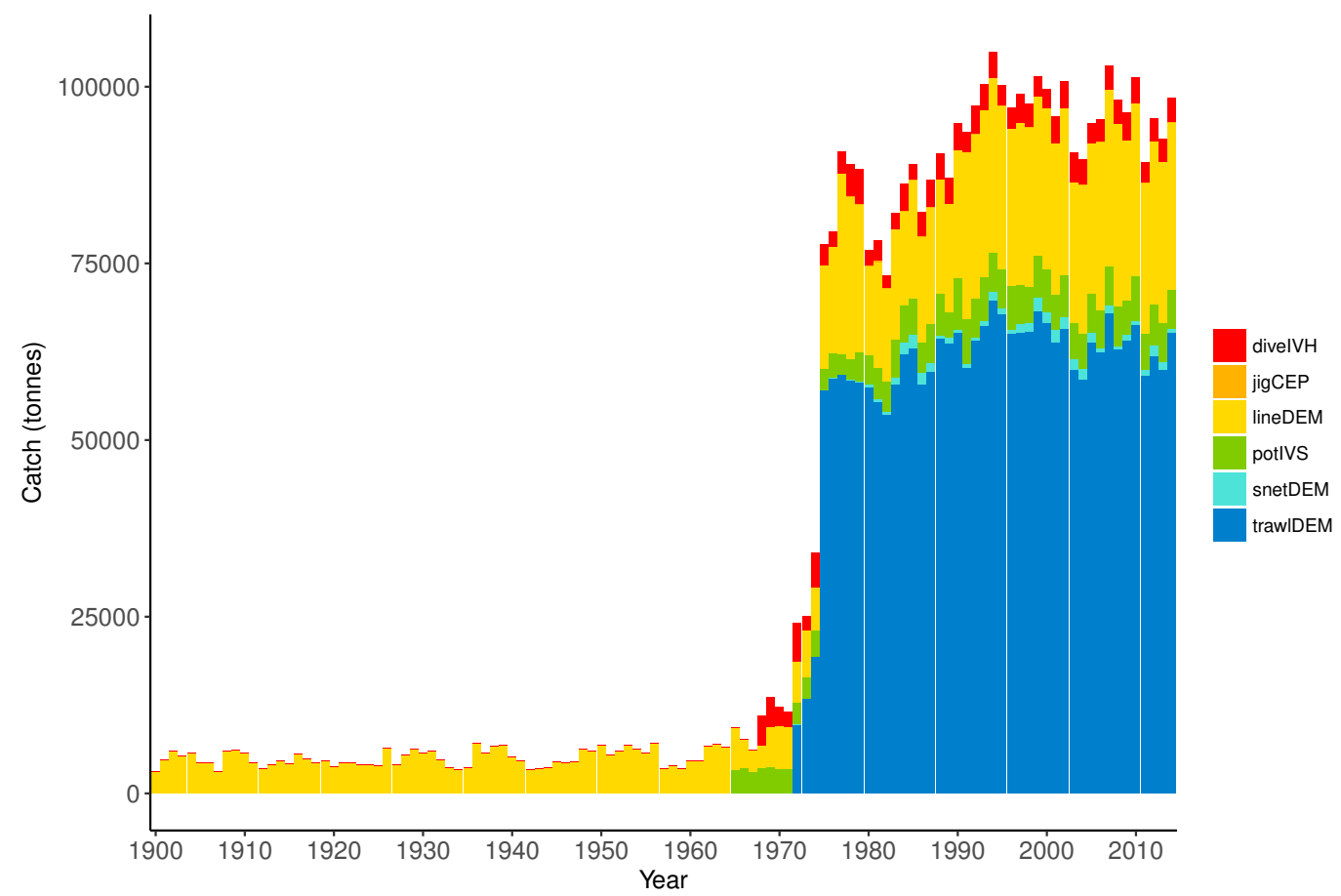

Figure 12: Total tonnes caught by fishing fleet from the Chatham Rise 1900-2014. Descriptions for the fleet codes are in Table 7 .

\subsection{Comparison with fisheries CPUE and Stock Assessment in- dices}

CRAM model estimates of biomass trends for key fisheries species were compared to CPUE and/or stock assessment indices where these were available. The Atlantis model captures the main biomass trends of hoki in response to historical fishing (Figure 13). Hoki are the largest fishery on the Chatham Rise, and has one of the most complex stock assessment models in New Zealand, with multiple areas, intricately defined migration, and annual recruitment deviates (McKenzie, 2016). The Atlantis model results are very similar to the stock assessment model results for hake and ling, and although the stock assessment models for these are not as complicated as hoki, they still have between-year recruitment deviates (Horn, 2013; McGregor, 2015) that are not present in the Atlantis model. The species group 'Invertebrate scavengers (commercial)' is primarily scampi, and the matched increase in the late 1990s-early 2000s is particularly pleasing as catches were fairly constant over this time (Tuck, 2016), so the increase is coming from dynamics within the model. Orange roughy is a close match to the stock assessment, even though this stock assessment model also has between-year recruitment deviates (Dunn 
and Doonan, in press) that are not in the Atlantis model. The magnitude of the stock assessment biomasses (unscaled) are compared to the CRAM biomasses in the inset boxplots in Figure 13. Hoki, hake, and invertebrate scavengers (commercial) were all close to one, indicating matched magnitudes between the stock assessment and CRAM biomasses. Ling were generally less than one, indicating the CRAM biomasses were larger than the stock assessment biomasses. Orange roughy were greater than one, indicating CRAM biomasses were smaller than the stock assessment biomasses.

\section{$7 \quad$ Skill assessment}

Quantitative skill assessments have become popular as part of assessing the performance of Atlantis models (Sturludottir et al., 2018; Ortega-Cisneros et al., 2017; Olsen et al., 2016). A quantitative skill assessment was carried out, comparing model biomass estimates with those from trawl surveys where available (O'Driscoll et al., 2011; Stevens et al., 2017). The trawl surveys target hoki, hake and ling, and as such the biomass indices are most reliable for these three species. The metrics selected were three of those suggested in Olsen et al. (2016) and Stow et al. (2009): Modelling efficiency (MEF) used to asses model predictions relative to the mean of the observations (Equation 6); Reliability index (RI) gives the average factor the model predictions differ from observations (Equation 7); Pearson's correlation (r) assesses whether model predictions are correlated with observations (Equation 8). The full set of CRAM biomass trajectories with historic catches and trawl survey indices are in Appendix D.

$$
\begin{gathered}
M E F=\frac{\sum_{y=1}^{Y}\left(O_{y}-\bar{O}\right)^{2}-\sum_{y=1}^{Y}\left(O_{y}-P_{y}\right)^{2}}{\sum_{y=1}^{Y}\left(O_{y}-\bar{O}\right)^{2}} \\
R I=\exp \sqrt{\frac{1}{Y} \sum_{y=1}^{Y}\left(\log \frac{O_{y}}{P_{y}}\right)^{2}} \\
r=\frac{\sum_{y=1}^{Y}\left(O_{y}-\bar{O}\right)\left(P_{y}-\bar{P}\right)}{\sqrt{\sum_{y=1}^{Y}\left(O_{y}-\bar{O}\right)^{2} \sum_{y=1}^{Y}\left(P_{y}-\bar{P}\right)^{2}}}
\end{gathered}
$$

where

$Y$ is the number of years for which there are observations, $O_{y}$ is the observed biomass in year $y$, 

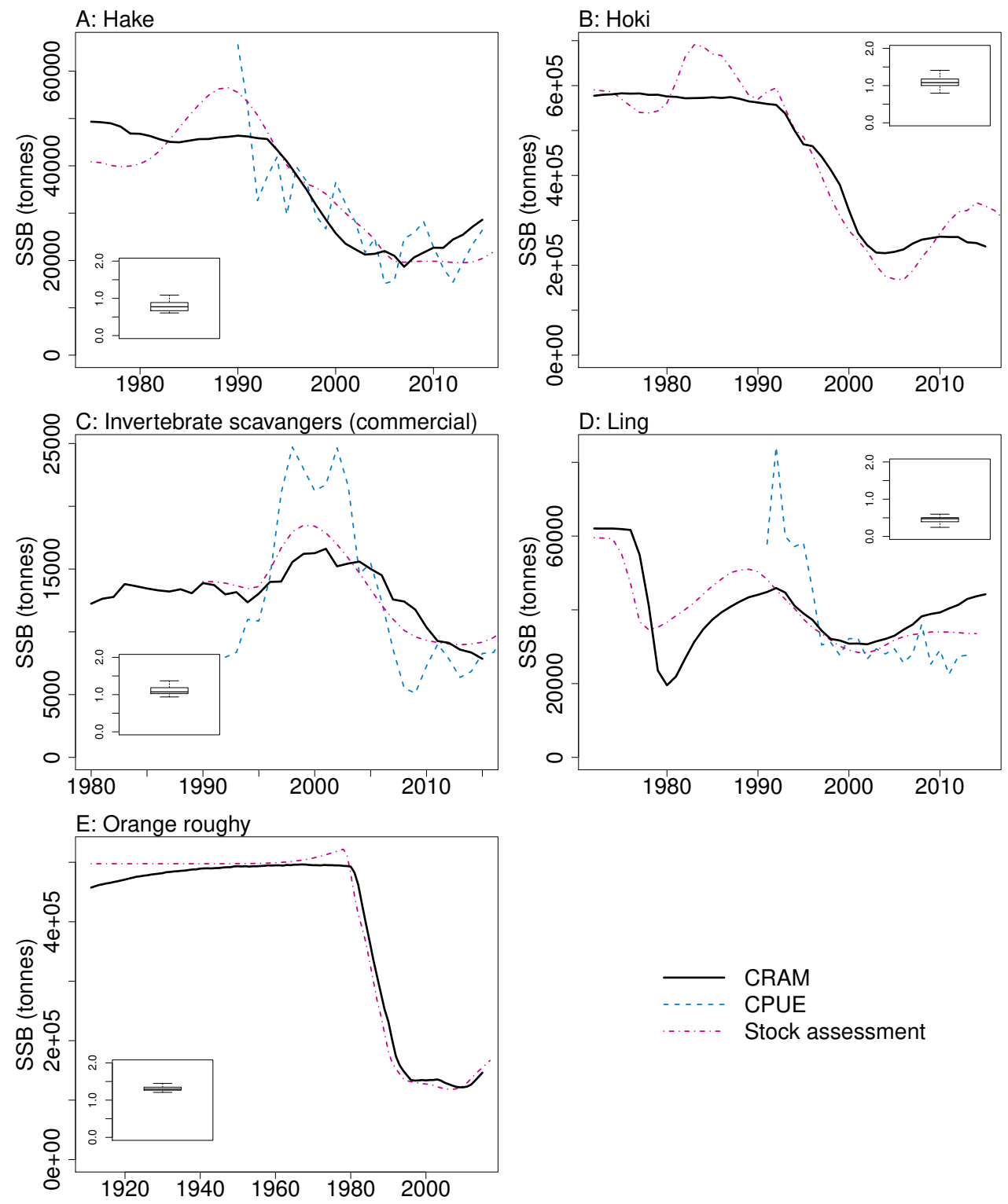

Figure 13: CRAM estimated spawning stock biomass (SSB) (black solid), stock assessment estimated SSB (red dot-dash), and CPUE (blue dash) where available for the hake (A), hoki (B), invertebrate scavengers (commercial) (primarily scampi) (C), ling (D), and orange roughy (E) . CPUE and stock assessment SSB were rescaled to match the mean of the CRAM estimated SSB. Inset boxplots show the range of values for the corresponding unscaled stock assessment SSB divided by the CRAM estimated SSB.

$P_{y}$ is the model biomass in year $y$

Each skill assessment metric was calculated using single point estimates from the trawl survey, and variants on RI and MEF were calculated allowing for the trawl survey 
estimated $95 \%$ confidence intervals. Both variants only penalised the skill metric for terms outside of the $95 \%$ confidence intervals of the trawl survey.

An MEF close to one indicates a close match between model predictions and observations, with zero indicating the mean of the observations is as close as the model predictions, and a negative value indicating the model predictions fit the observations worse than the mean of the observations. When the observed values are roughly stationary about the mean, as was the case for Ling, it is difficult for the predictions to improve on the mean of the observations. Ling stands out at approximately -2.5 when compared to the trawl survey point estimates, but as all the predicted points for ling sit within the $95 \%$ confidence interval, it receives a score of one when taking the bounds into account (Figure 14). Benthic invertivores (shallow) and lookdown dory are slightly negative with respect to the trawl survey point estimates.

A reliability index (RI) of one indicates the model predictions are exactly equal to the observations. RI greater than one (it cannot be less than one) indicates the factor by which observations are on average different to predictions. Since $\log (O / P)$ is equal to $-\log (P / O)$ and the RI squares these terms, an observation that is, for example, half the prediction will contribute exactly the same to this index as an observation that is twice a prediction. Hence, a RI of 2 indicates the observations differ from the predictions on average by 2 , but these could be generally twice as big or half as big, or both. All groups had RIs between 1 and 1.5 (Figure 14), indicating the observations are at worse on average $1.5 \times$ the predictions or $(2 / 3) \times$ the predictions.

A Pearson's correlation close to one indicates trends in the predictions vary with those in the observations, close to zero indicates there is little relationship between the trends, and negative indicates the predicted trends tend to be opposite from the observed trends. Hake and hoki had good correlation, close to 0.8. The other groups were either close to zero or negative (Figure 14). This is neither surprising nor concerning as the trawl survey estimates for these groups tend to have high variability and high CVs which are not taken into account here. 

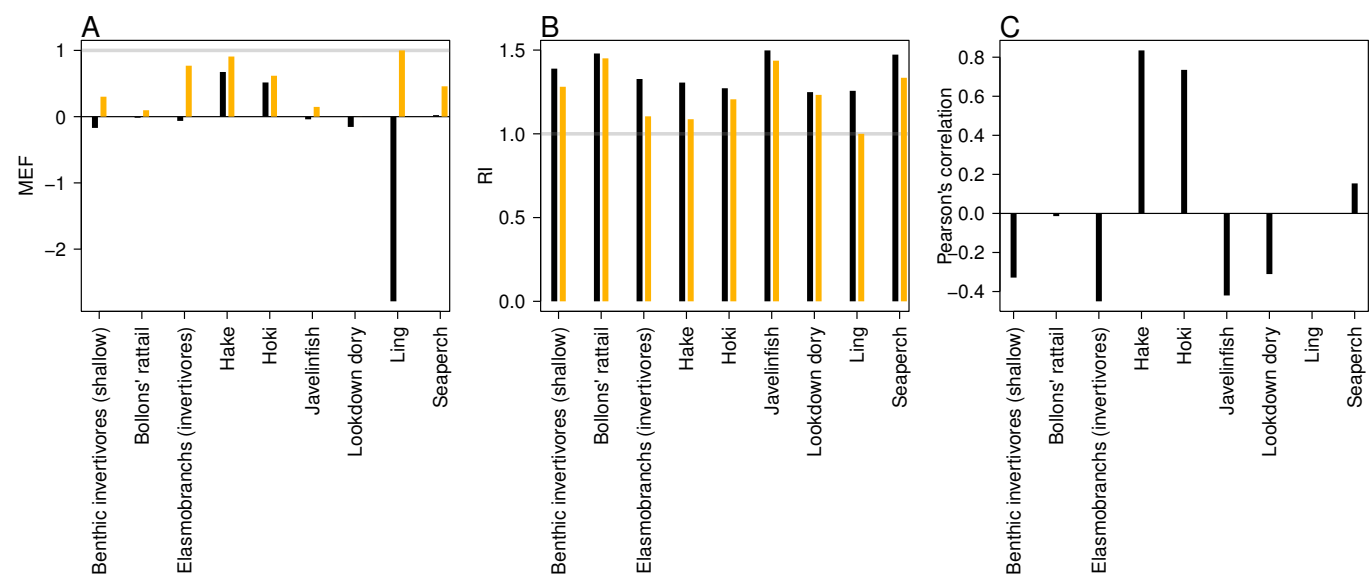

Figure 14: Skill assessment metrics MEF (A), RI (B) and Pearson's correlation (C) for CRAM species groups that have trawl survey indices for abundance. Metric definitions in Equations 6-8. The black bars are the skill metrics with respect to single point estimates from the trawl survey. The orange bars are the skill metrics with respect to the trawl survey $95 \%$ confidence intervals. The grey horizontal lines in the MEF and RI figures mark the value for a perfect fit, which is 1 for both of these.

\section{Bringing it together}

We qualitatively graded the species groups by how well they performed in the model and how well informed they were by data, information and other research (referred to as 'informance'). We compared these gradings with the keystone and responsiveness from Section 5.2. Figure 15 gives a visual guide for how well the most influential or responsive species groups did for informance and performance. While poor knowledge may not be concerning if paired with high responsiveness providing keystoneness is low (since the effects may be more limited to this single species group), the triple of highly responsive, a keystone species, and poorly defined may need consideration for future scenarios.

The groups that were highest for keystoneness and highest for informance and performance were hoki, orange roughy, benthic fish shallow (primarily oblique banded rattail), and hake. These all have abundance indices available, biological parameters, diet information, and all perform well with respect to these in the model. Hoki, orange roughy and hake (groups 1, 2, and 10 for keystoneness) have full stock assessments, which the model matches well. These are important groups for fisheries and will likely feature strongly in any fisheries scenarios explored with this model. 
Species groups Pelagic fish small (primarily myctophids) and Pelagic fish medium (primarily barracouta) were both high with respect to keystoneness and responsiveness, and while both were fairly well defined, these had some areas of poor model performance and do not have abundance indices to compare. The estimated length at age 1 from CRAM for small pelagic fish is larger than expected. This may be due to the size of recruits being larger than they should be, or the fish eating (and hence growing) more than they should in this first year. They are not so big that the effect transfers to the age-2's, as the age-2's are the correct size (Appendix B), so this is probably not influential on the model overall. Medium pelagics have slightly less natural mortality in the model than they should (Appendix C), and may be less responsive to fishing mortality as a result. As they are $7^{\text {th }}$ with respect to keystoneness and high for responsiveness, they could affect scenario outcomes and are worth considering when analysing results. They make up approximately $1 \%$ of the age-structured biomass.

Spiny dogfish were third for keystoneness, and low for responsiveness. They fit well to mortality and growth curves, but we do not have an index of abundance with which to compare the model simulated biomass in response to historical fishing. They make up approximately $5 \%$ of the age-structured biomass.

Epibenthic fish shallow (primarily common roughy) were $8^{\text {th }}$ for keystoneness, but low for responsiveness. They compare reasonably well to the trawl survey abundance index, but have less natural mortality in the model than they should. They make up approximately $1 \%$ of the age-structured biomass.

Species groups 'Seabird' and 'Cetacean other' are both poorly defined and rank within the top 10 for keystoneness, although lower for responsiveness. They are both composite groups, with Seabird consisting of all sea and shore birds, and Cetacean other consisting primarily of sperm whales, pilot whales and dolphins (Table 2). Scenarios explored in the future may benefit from sensitivity analysis with respect to these two groups to understand their effect on the outcomes, or perhaps some more work to better define them. 


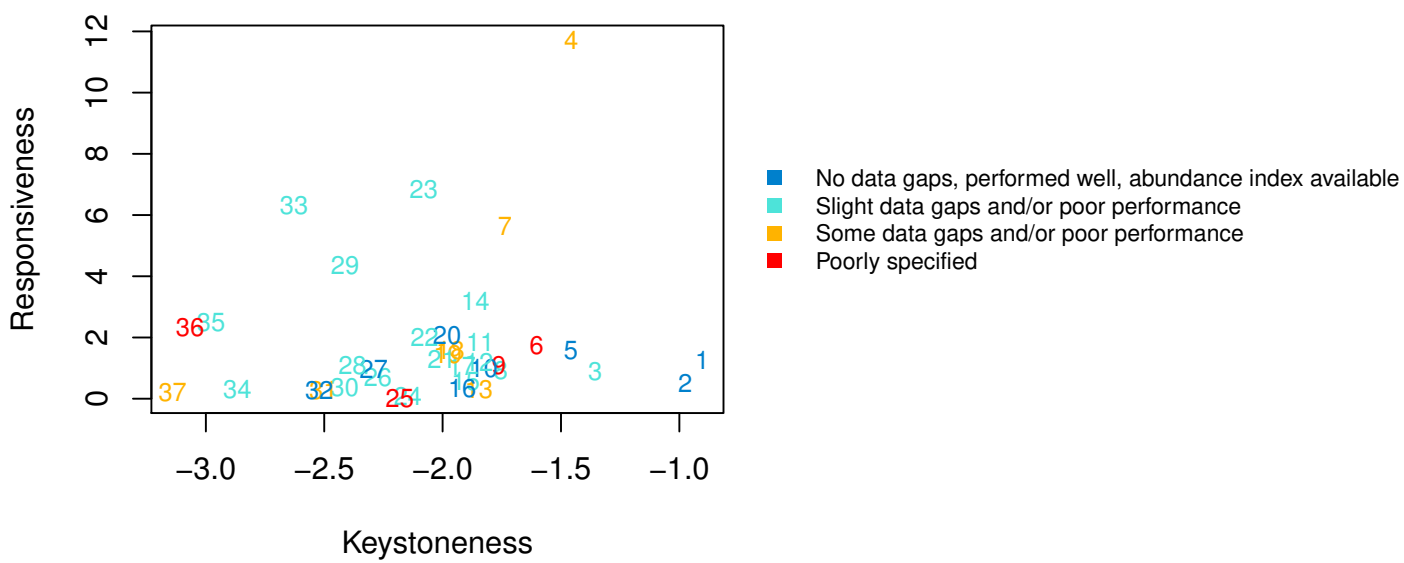

\begin{tabular}{|c|c|c|c|c|c|}
\hline . & 1 Hoki & I. & 14 Cephalopod other & - & 27 Javelinfish \\
\hline & 2 Orange roughy & in & 15 Mackerels & - & 28 Baxters dogfish \\
\hline a & 3 Spiny dogfish & = & 16 Bollons rattail & - & 29 Pelagic fish Ige \\
\hline = & 4 Pelagic fish sml & 四 & 17 Elasmobranch pisc & - & 30 Ghost shark \\
\hline घ & 5 Ben fish shal & ! & 18 Basketwork eel & - & 31 Dem fish pisc \\
\hline 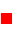 & 6 Seabird & = & 19 Arrow squid & - & 32 Elasmobranch invert \\
\hline [ & 7 Pelagic fish med & - & 20 Lookdown dory & - & 33 Invert comm scav \\
\hline = & 8 Epiben fish shal & II & 21 Invert comm herb & = & 34 Seaperch \\
\hline ם & 9 Cetacean other & = & 22 Epiben fish deep & घ & 35 Ben fish deep \\
\hline ] & 10 Hake & in & 23 Smooth oreo & घ & 36 Pinniped \\
\hline 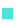 & 11 Ling & - & 24 Reef fish & - & 37 Rock lobster \\
\hline 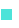 & 12 Shovelnosed dogfish & . & 25 Baleen whales & & \\
\hline & 13 Warehou & " & 26 Black oreo & & \\
\hline
\end{tabular}

Figure 15: Keystoneness (x-axis) and responsiveness (y-axis) with numbers showing keystoneness ranking and colours how well each species group was informed and/or performed in the model (legend).

\section{Discussion}

Ecosystem-based fisheries management (EBFM) is most likely to be achievable with the best information and modelling available (Heymans et al., 2010). The Chatham Rise Atlantis model presented here uses the wealth of data and information available for the Chatham Rise and its fisheries, and one of the best ecosystem models for exploring 'what-if' type questions (Plagányi, 2007) and ecosystem-level management strategy evaluation (Fulton et al., 2014). This comprehensive ecosystem model with realistic population dynamics and flow-on effects has the potential to be a valuable tool for understanding potential system-wide responses to fisheries management strategies in one of New Zealand's largest fishing grounds.

Some key aspects of this model performed convincingly well, such as responses of key fisheries species under fishing, realised diets, and the keystone rankings. That the key 
fisheries species results were very similar to the corresponding stock assessment results gives confidence that the model can respond to fishing in a way that is realistic, and that the ecosystem effects relative to these species are realistic. The stock assessment models fit data such as proportions at length and biomass indices with the help of betweenyear recruitment deviates, which are not present in the Chatham Rise Atlantis model. Conversely, the stock assessment models do not have time-varying natural mortality or growth rates, which are present in the Chatham Rise Atlantis model. As such, both modelling approaches achieve similar results but in very different ways. It is possible that the recruitment deviates in the stock assessments are proxy's for the other ecosystem dynamics that the Atlantis model is able to capture (or vice versa). However, the Atlantis model is too complex to fit comprehensively to data and is entirely deterministic. Hence, the Chatham Rise Atlantis model's ability to achieve the same results as the stock assessment models, that were fitted to data, is the best outcome.

Realistic diets and the influence of species groups on the rest of the ecosystem are key to the model's potential to explore and gain understanding of flow-on and cascading effects. It may be possible, for example, for a species to have realistic growth rates, but it is not very useful in an ecosystem modelling context if they do so by eating the wrong things. While they might respond realistically to direct pressure such as fishing, the flow-on effects would not likely reflect reality. Due to the complex nature of the Atlantis model, the summary of realised diets, together with analysing the keystoneness and responsiveness, are appropriate for determining whether species interactions are generally realistic, at a level of complexity that can be comprehensible. The Chatham Rise Atlantis model has realistic diet summaries for all species groups, and the top keystone species groups were all those we would expect to be most influential within this ecosystem. This is not to say the model could not benefit from further future work examining the realised diets at a finer scale - spatially, temporally, and by age-class.

Exploring the models sensitivity to initial conditions, while not an insignificant amount of work, may be worth doing at some stage in the future to add to our understanding of the models stability and persistence of dynamics. This has not, to the best of our knowledge, been done for Atlantis or OSMOSE models, likely due to the enormous complexity and computing resources required for the task. Sensitivities to initial conditions have been explored using Ecopath (Essington, 2007) and Ecopath with Ecosim (EwE) (Steenbeek et al., 2018). We are in the early stages of developing an EwE verison of CRAM, and it may be more feasible to explore ranges of initial conditions 
within the EwE framework, with the possibility of then adapting the analyses to the Atlantis model. Sensitivities of high-ranking keystone species, such as spiny dogfish, would be simpler to implement and may produce greater understanding of the model.

While there are some knowledge gaps, we have identified those most likely to influence scenario outcomes through analysing how influential (keystoneness) and influenced (responsiveness) the species groups are on and to each other. The composite groups 'cetacean other' and 'seabirds' were highly influential while poorly specified. Two solutions would be to a.) split these groups into smaller groups that can be better specified; b.) run sensitivities with respect to these groups when exploring scenarios using this model. As option a.) would require more data than we currently have available, option b.) is the only currently viable option.

The oceanographic variables based on years 1996-2004 were found to be influential on the simulated biomasses of the species groups, and the order they were repeated changed the results, with CVs of up to nearly $80 \%$. This suggests scenarios carried out using this model need to consider oceanographic variability in simulated results, using multiple runs with different oceanographic years repeated or changing the order. This may be true for many ecosystem models, but we are unaware of similar analyses completed elsewhere. Further work understanding which species groups and/or spatial areas of the model are most affected by oceanographic variability might be helpful in understanding potential impacts on scenario results.

As Atlantis is spatially resolved, there is scope for a greater emphasis on the effects of features such as habitats, depth, and oceanographic features on responses to fisheries management scenarios. Kaplan et al. (2012) explored spatially resolved fisheries management scenarios using an Atlantis model of the California Current, including areas closed to bottom-contact fishing gear, and varying spatial management specification relating to Marine Protected Areas (MPAs). In the Chatham Rise ecosystem, it may be that repeating cooler or warmer years such as carried out in this study could influence the spatial distribution of some species. This could in turn influence the range of plausible responses to fisheries management scenarios that have a spatial aspect, such as MPAs, the effects of different fishing gear, serial depletion of fishing grounds, and potential effects on by-catch species that may overlap spatially with species that are targeted by fisheries. 
While we have confidence in this model for exploring fisheries type scenarios in support of an ecosystem based approach to fisheries management, the model still stands to benefit from further exploration. Key to understanding the implications of any results from such a complex model is to first ask what in the model is producing the results, before asking what it tells us about the system.

\section{Conclusions}

The analyses presented in this paper are intended to set the stage for an understanding of how the model is specified and how it behaves, but it is not exhaustive. The model produces similar results to fisheries stock assessment models for key fisheries species, and the population dynamics and system interactions are realistic. Confidence intervals based on bootstrapping oceanographic variables were fairly narrow for most species groups, with diatoms, carnivorous zooplankton and labile detritus having the largest CVs. The species groups with the highest keystoneness were orange roughy, hoki, pelagic fish small (primarily myctophids) and spiny dogfish. The model components that have knowledge gaps and are most likely to influence model results were oceanographic variables, and the aggregate species groups 'seabird' and 'cetacean other'. We recommend applications of the model include alternatives that vary these components. It is expected that any future use of the model will add first to our understanding of the model, and then possibly to our understanding of the ecosystem.

\section{Acknowledgements}

Mark Hadfield for development of the ROMS model for oceanographic variables. Bec Gorton (CSIRO) for converting the ROMS variables into Atlantis model inputs. Ian Tuck for providing a comprehensive internal review of the manuscript. Cliff Law and Graham Rickard (NIWA) for help with ocean physics data and conversions. Matt Pinkerton for trophic level results from stable isotope analyses and visible band radiation at sea surface data. James Bell, Victoria University supervisor.

\section{References}

Ainsworth, C. H., Schirripa, M. J., Morzaria-Luna, H. N., 2015. An Atlantis ecosystem model for the Gulf of Mexico supporting integrated ecosystem assessment. NOAA 
technical memorandum NMFS-SEFC, 676.

Audzijonyte, A., Gorton, R., Kaplan, I., Fulton, E. A., 2017. Atlantis users guide part i: General overview, physics \& ecology.

Beentjes, M. P., Stevenson, M. L., 2009. Inshore trawl survey of Canterbury Bight and Pegasus Bay, May-June 2008 (KAH0806). New Zealand Fisheries Assessment Report $57,105 \mathrm{p}$.

Breen, P. A., Kim, S. W., Andrew, N. L., 2003. A length-based Bayesian stock assessment model for the New Zealand abalone Haliotis iris. Marine and Freshwater Research 54 (5), 619-634.

Broekhuizen, N., Gurney, W., Jones, A., Bryant, A., 1994. Modelling compensatory growth. Functional Ecology 8(6), 770-782.

Bull, B., Francis, R., Dunn, A., McKenzie, A., Gilbert, D., Smith, M., Bian, R., 2012. CASAL (c++ algorithmic stock assessment laboratory): Casal user manual v2.30-2012/03/21. NIWA Technical Report 135.

Clarke, M., Connolly, P., Bracken, J., 2002. Age estimation of the exploited deepwater shark Centrophorus squamosus from the continental slopes of the Rockall Trough and Porcupine Bank. Journal of Fish Biology 60 (3), 501-514.

Collie, J. S., Botsford, L. W., Hastings, A., Kaplan, I. C., Largier, J. L., Livingston, P. A., Plagányi, É., Rose, K. A., Wells, B. K., Werner, F. E., 2016. Ecosystem models for fisheries management: finding the sweet spot. Fish and Fisheries 17 (1), 101-125.

Cubillos, L., Alarcón, R., Vilugran, A., Sepúlveda, A., George-Nascimento, M., Araya, M. Medina, J., Zambrano, M., Guzman, L., Martinez, J., Peñailillo, R., Gili, Z. Young, V. A. V. B. L. M. L., 1998. Validación de los métodos aplicados en la determinación de edad y crecimiento, y determinación de la mortalidad del jurel en la zona centro sur. Informe Final Proyecto FIP, 95-10, 170 p.

Deepwater Group, 2018. Deepwater Groups fisheries certification programme. Tech. rep., http://deepwatergroup.org/certification/ [Accessed 7 June 2018].

Deutsches Ozeanographisches Datenzentrum, Bundesamt Fur Seeschifffahrt Und Hydrographie, G., 2006. The world ocean circulation experiment (woce) global hydrographic climatology.

URL http://rda.ucar.edu/datasets/ds285.4/ 
Dunn, M., Anderson, O., Doonan, I., 2008. An evaluation of stock status for orange roughy on the east and south chatham rise in 2008. New Zealand Fisheries Assessment Report 65, 30 .

Dunn, M., Doonan, I., in press. Assessment of the Chatham Rise orange roughy stocks for 2017. New Zealand Fisheries Assessment Report.

Dunn, M., Horn, P., Connell, A., Stevens, D., Forman, J., Pinkerton, M., Griggs, L., Notman, P., Wood, B., 2009. Ecosystem-scale trophic relationships: diet composition and guild structure of middle-depth fish on the chatham rise. Tech. rep., Final Research Report for Ministry of Fisheries Research Project ZBD2004-02 Objectives $1-5$.

Essington, T. E., 2007. Evaluating the sensitivity of a trophic mass-balance model (ecopath) to imprecise data inputs. Canadian Journal of Fisheries and Aquatic Sciences $64(4), 628-637$.

Fournier, D., Sibert, J. R., Majkowski, J., Hampton, J., 1990. Multifan a likelihoodbased method for estimating growth parameters and age composition from multiple length frequency data sets illustrated using data for southern bluefin tuna (Thunnus maccoyii). Canadian journal of fisheries and aquatic sciences 47 (2), 301-317.

Fulton, E., Smith, A., Smith, D., 2007. Alternative management strategies for southeast australian commonwealth fisheries: stage 2: quantitative management strategy evaluation.

Fulton, E. A., 2010. Approaches to end-to-end ecosystem models. Journal of Marine Systems 81 (1-2), 171-183.

Fulton, E. A., Smith, A. D., Smith, D. C., Johnson, P., 2014. An integrated approach is needed for ecosystem based fisheries management: insights from ecosystem-level management strategy evaluation. PLoS One 9 (1), e84242.

Garcia, H. E., Locarnini, R. A., Boyer, T. P., Antonov, J. I., Baranova, O., Zweng, M., Reagan, J., Johnson, D., 2013a. World ocean atlas 2013, volume 3: Oxygen. Mishonov Technical Ed.; NOAA Atlas NESDIS 73, 27.

Garcia, H. E., Locarnini, R. A., Boyer, T. P., Antonov, J. I., Baranova, O., Zweng, M., Reagan, J., Johnson, D., 2013b. World ocean atlas 2013, volume 4: Nutrients. Mishonov Technical Ed.; NOAA Atlas NESDIS 73, 25. 
Hadfield, M. G., Rickard, G. J., Uddstrom, M. J., 2007. A hydrodynamic model of chatham rise, new zealand. New Zealand Journal of Marine and Freshwater Research 41 (2), 239-264.

Hanchet, S. M., 1986. The Distribution and Abundance, Reproduction, Growth, and Life History Characteristics of the Spiny Dogfish, Squalus Acanthias (Linnaeus), in New Zealand: A Thesis Submitted for the Degree of Doctor of Philosophy at the University of Otago, Dunedin, New Zealand. Ph.D. thesis, University of Otago.

Heath, R., 1985. A review of the physical oceanography of the seas around New Zealand - 1982. New Zealand journal of marine and freshwater research 19 (1), 79-124.

Heymans, J. J., Howell, K. L., Ayers, M., Burrows, M. T., Gordon, J. D., Jones, E. G., Neat, F., 2010. Do we have enough information to apply the ecosystem approach to management of deep-sea fisheries? An example from the West of Scotland. ICES Journal of Marine Science 68 (2), 265-280.

Hoegh-Guldberg, O., Bruno, J. F., 2010. The impact of climate change on the worlds marine ecosystems. Science 328 (5985), 1523-1528.

Horn, P., 2002. Age estimation of barracouta (Thyrsites atun) off southern New Zealand. Marine and Freshwater Research 53, 1169-1178.

Horn, P., 2013. Stock assessment of hake (Merluccius australis) on the Chatham Rise (HAK 4) and off the west coast of South Island (HAK 7) for the 2012-13 fishing year. New Zealand Fisheries Assessment Report 31, 62.

Horn, P. L., Sutton, C. P., 1996. Validated ages, growth, and productivity parameters for silver warehou (Seriolella punctata) off the south and east coasts of south island, new zealand. New Zealand Journal of Marine and Freshwater Research 30 (3), 301-312.

Irvine, S. B., Stevens, J. D., Laurenson, L. J., 2006a. Comparing external and internal dorsal-spine bands to interpret the age and growth of the giant lantern shark, Etmopterus baxteri (Squaliformes: Etmopteridae). Environmental Biology of Fishes $77(3-4), 253-264$.

Irvine, S. B., Stevens, J. D., Laurenson, L. J., 2006b. Surface bands on deepwater squalid dorsal-fin spines: an alternative method for ageing Centroselachus crepidater. Canadian journal of fisheries and aquatic sciences 63 (3), 617-627.

Kaplan, I. C., Horne, P. J., Levin, P. S., 2012. Screening california current fishery management scenarios using the atlantis end-to-end ecosystem model. Progress in Oceanography 102, 5-18. 
Kaplan, I. C., Marshall, K. N., 2016. A guinea pig's tale: learning to review end-toend marine ecosystem models for management applications. ICES Journal of Marine Science 73 (7), 1715-1724.

Kochkin, P., 1994. Age determination and estimate of growth rate for the Peruvian jack mackerel, Trachurus symmetricus murphyi. Journal of Ichthyology 34 (3), 39-50.

Libralato, S., Christensen, V., Pauly, D., 2006. A method for identifying keystone species in food web models. Ecological Modelling 195 (3-4), 153-171.

Link, J. S., 2010. Adding rigor to ecological network models by evaluating a set of pre-balance diagnostics: a plea for prebal. Ecological Modelling 221 (12), 1580-1591.

Link, J. S., Browman, H. I., 2017. Operationalizing and implementing ecosystem-based management. ICES Journal of Marine Science 74 (1), 379-381.

Link, J. S., Fulton, E. A., Gamble, R. J., 2010. The northeast us application of atlantis: a full system model exploring marine ecosystem dynamics in a living marine resource management context. Progress in Oceanography 87 (1), 214-234.

Locarnini, R. A., Mishonov, A. V., Antonov, J. I., Boyer, T. P., Garcia, H. E., Baranova, O. K., Zweng, M. M., Paver, C. R., Reagan, J. R., Johnson, D. R., Hamilton, M., Seidov, D., 2013. World ocean atlas 2013, volume 1: Temperature. Mishonov Technical Ed.; NOAA Atlas NESDIS 73, 44.

Long, R. D., Charles, A., Stephenson, R. L., 2015. Key principles of marine ecosystembased management. Marine Policy 57, 53-60.

Mackay, K., 2000. Database documentation: trawl. Tech. rep., NIWA Internal Report.

Marine Stewardship Council, 2014. MSC Fisheries certification requirements and guidance v2.0, 528p.

Maunder, M., Starr, P., 1995. Rock lobster standardised cpue analysis. new zealand fisheries assessment research document 95/11. 28 p. Unpublished report held in NIWA Greta Point library, Wellington.

McGregor, V., 2015. Stock assessment of ling (Genypterus blacodes) on the Chatham Rise (LIN 3\&4) for the 2014-15 fishing year. New Zealand Fisheries Assessment Research Document 82.

McKenzie, A., 2016. Assessment of hoki (Macruronus novaezelandiae) in 2015. New Zealand Fisheries Assessment Report 01, 88. 
Ministry for Primary Industries, 2008. Harvest Strategy Standard for New Zealand Fisheries. Wellington, New Zealand, 27p.

Ministry for Primary Industries, 2016. Fisheries Assessment Plenary, May 2016 stock assessments and yield estimates. Compiled by the Fisheries Science Group, Ministry for Primary Industries, Wellington, New Zealand., 1556.

Ministry for Primary Industries, 2017. Report from the fisheries assessment plenary. stock assessments and yield estimates. Ministry of Fisheries Report.

Moore, C., Mills, M., Arrigo, K., Berman-Frank, I., Bopp, L., Boyd, P., Galbraith, E., Geider, R., Guieu, C., Jaccard, S., Jickells, T., La Roche, J., Lenton, T., Mahowald, N., Marañón, E., Marinov, I., Moore, J., Nakatsuka, T., Oschlies, A., Saito, M., Thingstad, T., Tsuda, A., Ulloa, O., 2013. Processes and patterns of oceanic nutrient limitation. Nature Geoscience 6 (9), 701.

O'Driscoll, R., MacGibbon, D., Fu, D., Lyon, W., Stevens, D., 2011. A review of hoki and middle-depth trawl surveys of the Chatham Rise, January 1992-2010. New Zealand Fisheries Assessment Report 47, 814.

Olsen, E., Fay, G., Gaichas, S., Gamble, R., Lucey, S., Link, J. S., 2016. Ecosystem model skill assessment. yes we can! PloS one 11 (1), e0146467.

Ortega-Cisneros, K., Cochrane, K., Fulton, E. A., 2017. An atlantis model of the southern benguela upwelling system: Validation, sensitivity analysis and insights into ecosystem functioning. Ecological modelling 355, 49-63.

Paul, L., Horn, P., 2009. Age and growth of sea perch (Helicolenus percoides) from two adjacent areas off the east coast of South Island, New Zealand. Fisheries Research 95 (2-3), 169-180.

Plagányi, É. E., 2007. Models for an ecosystem approach to fisheries. No. 477. Food \& Agriculture Org.

Rose, K. A., 2012. End-to-end models for marine ecosystems: Are we on the precipice of a significant advance or just putting lipstick on a pig? Scientia Marina 76 (1), $195-201$.

Savina, M., Grist, E., Boschetti, F., Fulton, E., McDonald, A., 2005. Implementation of the atlantis ecological model in the westernport scoping study.

Smith, D. C., Fulton, E. A., Apfel, P., Cresswell, I. D., Gillanders, B. M., Haward, M., Sainsbury, K. J., Smith, A. D., Vince, J., Ward, T. M., 2017. Implementing marine 
ecosystem-based management: lessons from australia. ICES Journal of Marine Science 74 (7), 1990-2003.

Smith, M. D., Fulton, E. A., Day, R. W., 2015. Using an atlantis model of the southern benguela to explore the response of ecosystem indicators for fisheries management. Environmental Modelling \& Software 69, 23-41.

Stecken, M., Failler, P., 2016. Ecosystem approach to fisheries and marine ecosystem modelling: review of current approaches. Journal of Fisheries \& Livestock Production $4(4)$.

Steenbeek, J., Corrales, X., Platts, M., Coll, M., 2018. Ecosampler: A new approach to assessing parameter uncertainty in ecopath with ecosim. SoftwareX 7, 198-204.

Stevens, D., Hurst, R., Bagley, N., 2011a. Feeding habits of New Zealand fishes: a literature review and summary of research trawl database records 1960 to 2000 . New Zealand Aquatic Environment and Biodiversity Report 85.

Stevens, D., O’Driscoll, R., Ballara, S., Ladroit, Y., 2017. Trawl survey of hoki and middle-depth species on the Chatham Rise, January 2016 (TAN1601). New Zealand Fisheries Assessment Report 8, 131.

Stevens, D., Smith, M., Grimes, P., Devine, J., Sutton, C., MacGibbon, D., Maolagáin, C., 2010. Age, growth, and maturity of four New Zealand rattail species. NZ Aquat. Environ. Biodiv. Rept (59), 39.

Stevens, D. W., Hurst, R. J., Bagley, N. W., 2011b. Feeding habits of New Zealand fishes: a literature review and summary of research trawl database records 1960 to 2000. Ministry of Fisheries.

Stewart, B., Smith, D., 1994. Development of methods to age commercially important dories and oreos. Corporation, Project 91/36.

Stow, C. A., Jolliff, J., McGillicuddy Jr, D. J., Doney, S. C., Allen, J. I., Friedrichs, M. A., Rose, K. A., Wallhead, P., 2009. Skill assessment for coupled biologi$\mathrm{cal} /$ physical models of marine systems. Journal of Marine Systems 76 (1-2), 4-15.

Sturludottir, E., Desjardins, C., Elvarsson, B., Fulton, E. A., Gorton, R., Logemann, K., Stefansson, G., 2018. End-to-end model of Icelandic waters using the Atlantis framework: Exploring system dynamics and model reliability. Fisheries Research 207, $9-24$. 
Sutton, C., 1999. Ageing methodology, growth parameters, and estimates of mortality for giant stargazer (Kathetostoma giganteum) from the east and south coasts of the South Island. New Zealand Fisheries Assessment Research Document 99/15. 19 p. Unpublished report held in NIWA library, Wellington 22.

Tuck, I., 2016. Characterisation and a length-based assessment model for scampi (Metanephrops challengeri) on the Mernoo Bank (SCI 3).

Tuck, I. D., Cole, R., Devine, J. A., 2009. Ecosystem indicators for New Zealand fisheries. Ministry of Fisheries.

Uddstrom, M. J., Oien, N. A., 1999. On the use of high-resolution satellite data to describe the spatial and temporal variability of sea surface temperatures in the New Zealand region. Journal of Geophysical Research: Oceans 104 (C9), 20729-20751.

Young, J., Bulman, C., Blaber, S., Wayte, S., 1988. Age and growth of the lanternfish Lampanyctodes hectoris (Myctophidae) from eastern Tasmania, Australia. Marine Biology 99 (4), 569-576.

Zweng, M., Reagan, J., Antonov, J., Locarnini, R., Mishonov, A., Boyer, T., Garcia, H., Baranova, O., Johnson, D., D.Seidov, Biddle, M., 2013. World ocean atlas 2013, volume 2: Salinity. Mishonov Technical Ed.; NOAA Atlas NESDIS 73, 39. 


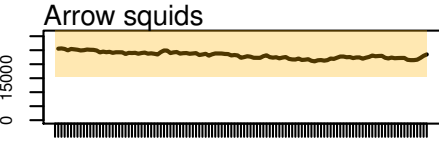

$\begin{array}{llllllll}1900 & 1916 & 1932 & 1948 & 1964 & 1980 & 1996 & 2012\end{array}$

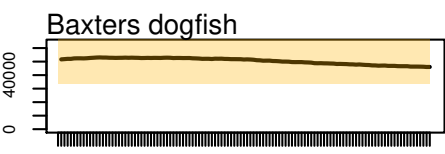

$\begin{array}{llllllll}1900 & 1916 & 1932 & 1948 & 1964 & 1980 & 1996 & 2012\end{array}$

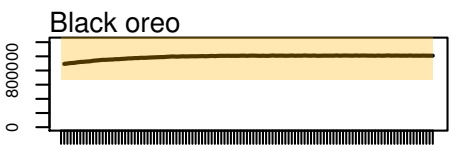

$\begin{array}{lllllllll}1900 & 1916 & 1932 & 1948 & 1964 & 1980 & 1996 & 2012\end{array}$

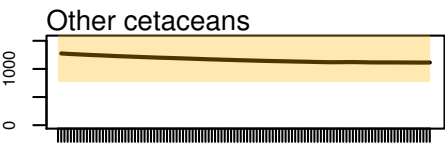

$\begin{array}{llllllll}1900 & 1916 & 1932 & 1948 & 1964 & 1980 & 1996 & 2012\end{array}$

Elasmobranchs

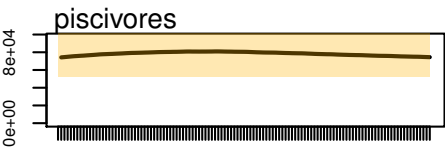

$\begin{array}{llllllll}1900 & 1916 & 1932 & 1948 & 1964 & 1980 & 1996 & 2012\end{array}$

Ghost sharks
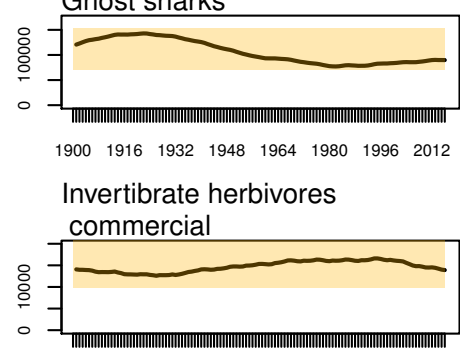

$\begin{array}{llllllll}1900 & 1916 & 1932 & 1948 & 1964 & 1980 & 1996 & 2012\end{array}$

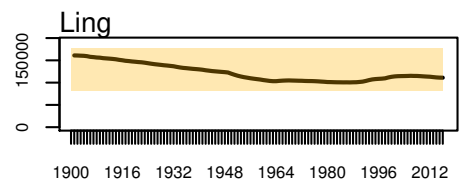

Baleen whales

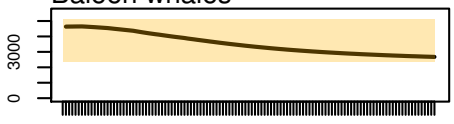

$\begin{array}{llllllll}1900 & 1916 & 1932 & 1948 & 1964 & 1980 & 1996 & 2012\end{array}$

Benthic invertivores
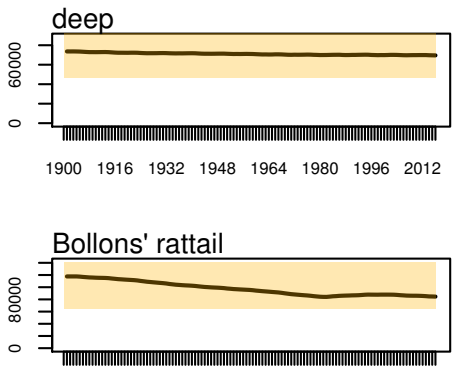

$\begin{array}{llllllll}1900 & 1916 & 1932 & 1948 & 1964 & 1980 & 1996 & 2012\end{array}$

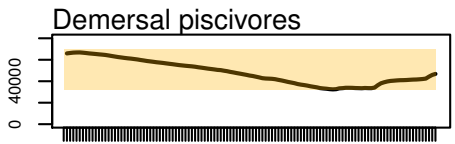

$\begin{array}{llllllll}1900 & 1916 & 1932 & 1948 & 1964 & 1980 & 1996 & 2012\end{array}$

Epibenthic invertivores

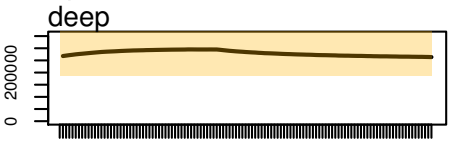

$\begin{array}{llllllll}1900 & 1916 & 1932 & 1948 & 1964 & 1980 & 1996 & 2012\end{array}$

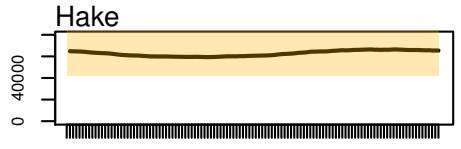

$\begin{array}{llllllll}1900 & 1916 & 1932 & 1948 & 1964 & 1980 & 1996 & 2012\end{array}$

Invertebrate scavangers

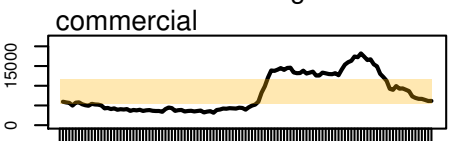

$\begin{array}{llllllll}1900 & 1916 & 1932 & 1948 & 1964 & 1980 & 1996 & 2012\end{array}$

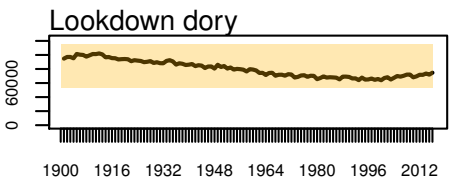

Basketwork eel

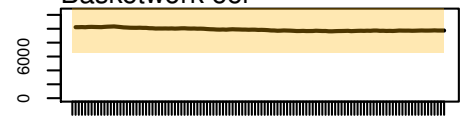

$\begin{array}{llllllll}1900 & 1916 & 1932 & 1948 & 1964 & 1980 & 1996 & 2012\end{array}$

Benthic invertivores shallow
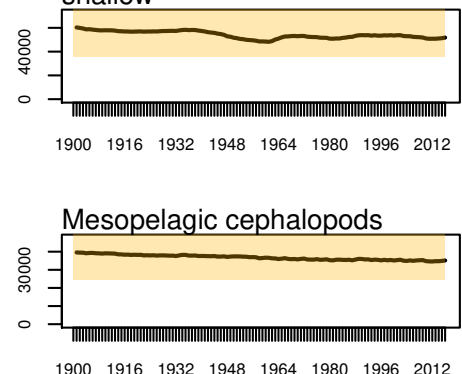

$\begin{array}{lllllllll}1900 & 1916 & 1932 & 1948 & 1964 & 1980 & 1996 & 2012\end{array}$

Elasmobranchs

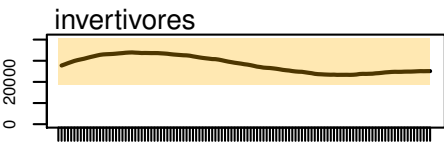

$\begin{array}{llllllll}1900 & 1916 & 1932 & 1948 & 1964 & 1980 & 1996 & 2012\end{array}$

Epibenthic invertivores
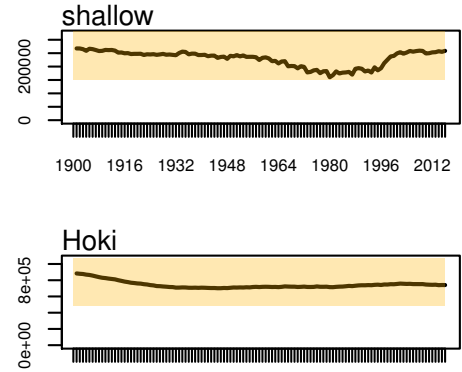

$\begin{array}{llllllll}1900 & 1916 & 1932 & 1948 & 1964 & 1980 & 1996 & 2012\end{array}$

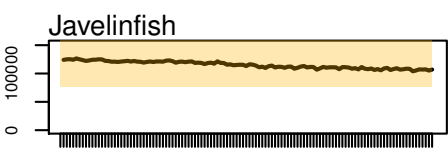

$\begin{array}{lllllllll}1900 & 1916 & 1932 & 1948 & 1964 & 1980 & 1996 & 2012\end{array}$

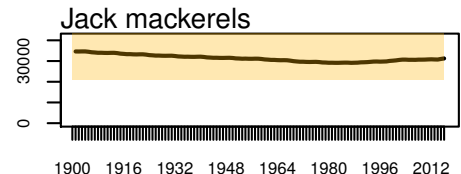




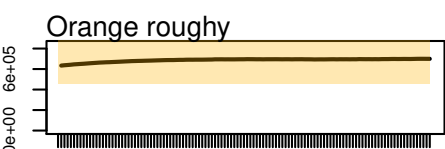

$\begin{array}{llllllll}1900 & 1916 & 1932 & 1948 & 1964 & 1980 & 1996 & 2012\end{array}$

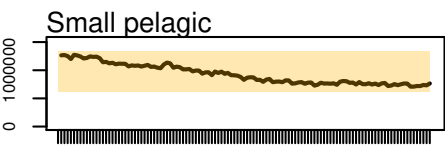

$\begin{array}{llllllll}1900 & 1916 & 1932 & 1948 & 1964 & 1980 & 1996 & 2012\end{array}$

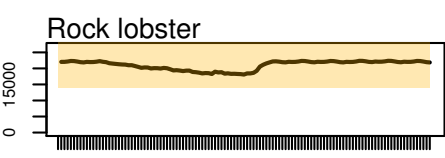

$\begin{array}{llllllll}1900 & 1916 & 1932 & 1948 & 1964 & 1980 & 1996 & 2012\end{array}$

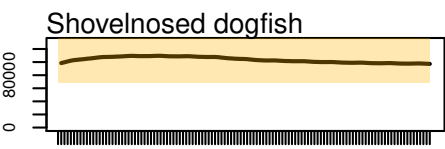

$\begin{array}{llllllll}1900 & 1916 & 1932 & 1948 & 1964 & 1980 & 1996 & 2012\end{array}$

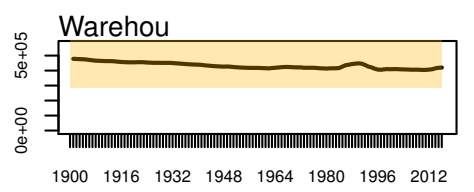

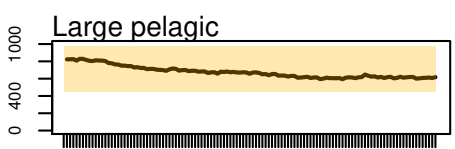

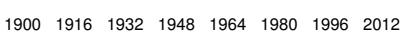

Pinnipeds

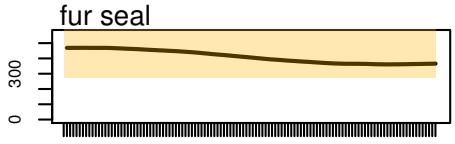

$\begin{array}{llllllll}1900 & 1916 & 1932 & 1948 & 1964 & 1980 & 1996 & 2012\end{array}$

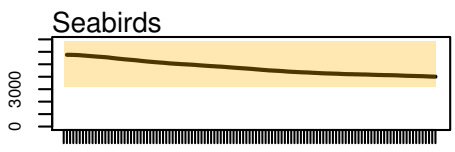

$\begin{array}{llllllll}1900 & 1916 & 1932 & 1948 & 1964 & 1980 & 1996 & 2012\end{array}$

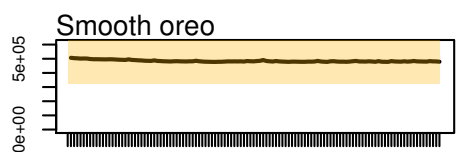

$\begin{array}{llllllll}1900 & 1916 & 1932 & 1948 & 1964 & 1980 & 1996 & 2012\end{array}$
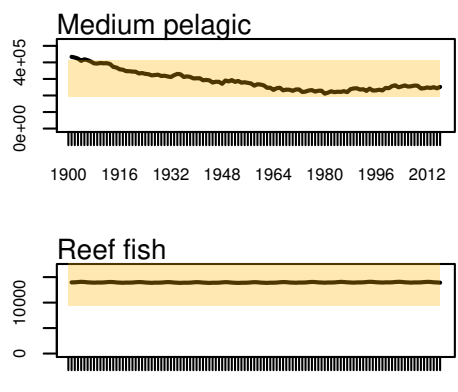

$\begin{array}{llllllll}1900 & 1916 & 1932 & 1948 & 1964 & 1980 & 1996 & 2012\end{array}$

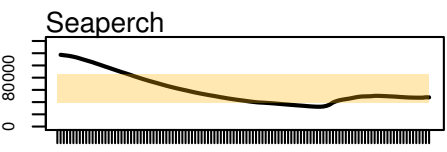

$\begin{array}{llllllll}1900 & 1916 & 1932 & 1948 & 1964 & 1980 & 1996 & 2012\end{array}$

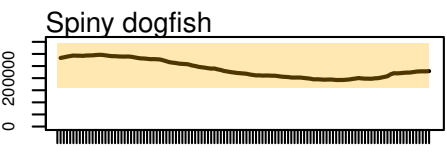

$\begin{array}{llllllll}1900 & 1916 & 1932 & 1948 & 1964 & 1980 & 1996 & 2012\end{array}$ 


\section{Appendix B: Size-at-age}

Size-at-age using values based on literature (Table 6) where available (orange shaded shows 95\% confidence intervals using CV 10\%) and from CRAM simulated years 1900-2015 (boxplots).

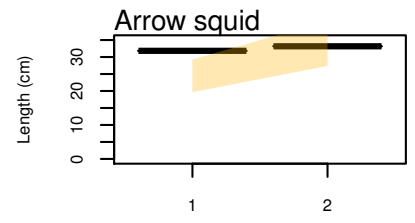

Age (years)

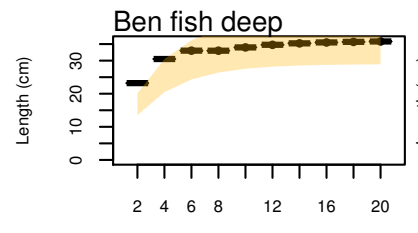

Age (years)

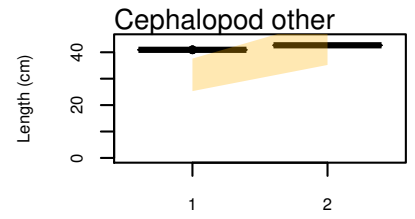

Age (years)
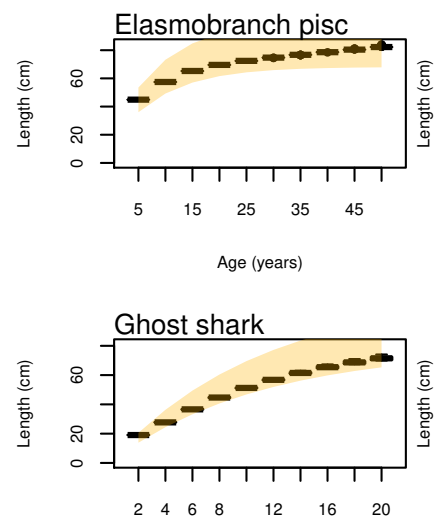

Age (years)

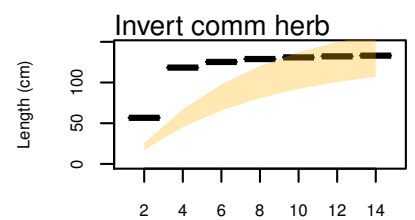

Age (years)

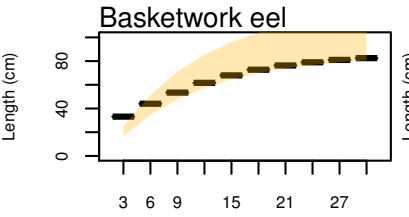

Age (years)

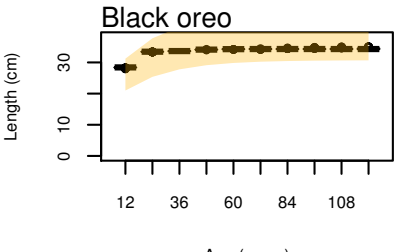

Age (years)

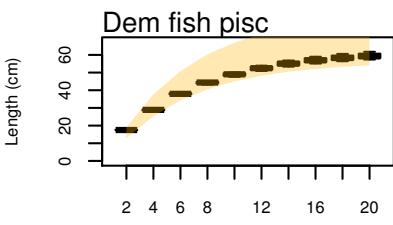

Age (years)
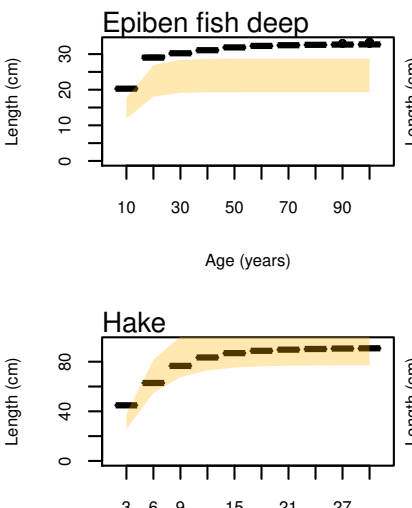

Age (years)

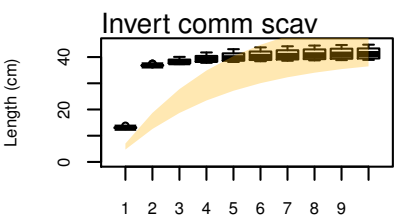

Age (years)

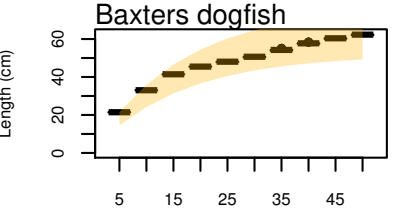

Age (years)

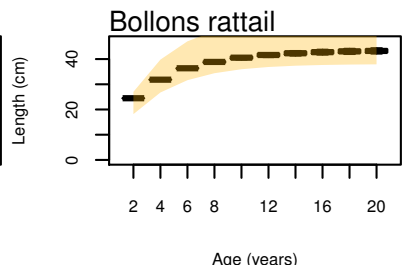

Age (years)

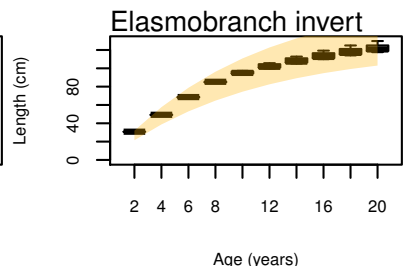

Age (years)
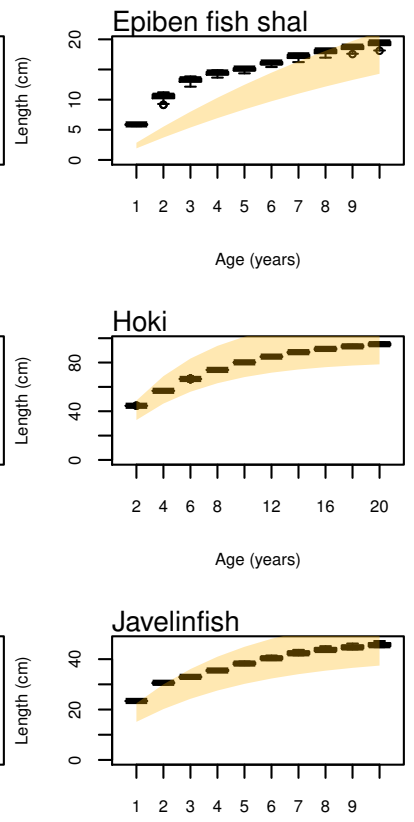

Age (years) 


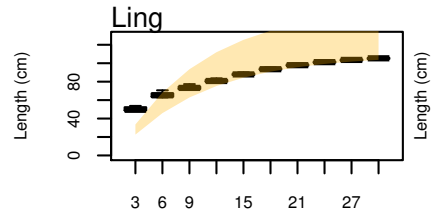

Age (years)
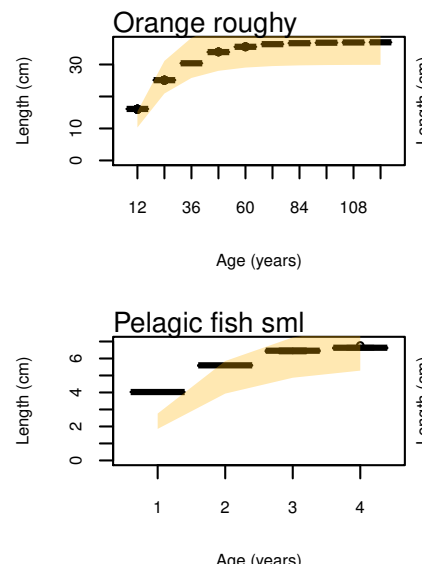

Age (years)

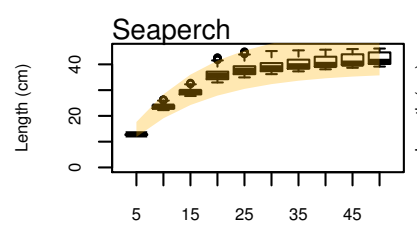

Age (years)

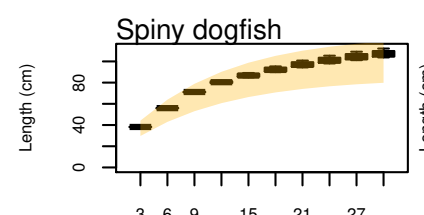

$\begin{array}{llllll}3 & 6 & 9 & 15 & 21 & 27\end{array}$

Age (years)

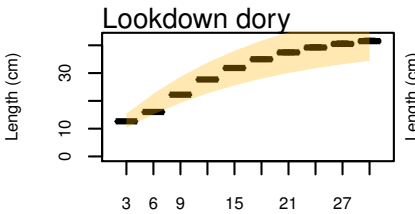

Age (years)
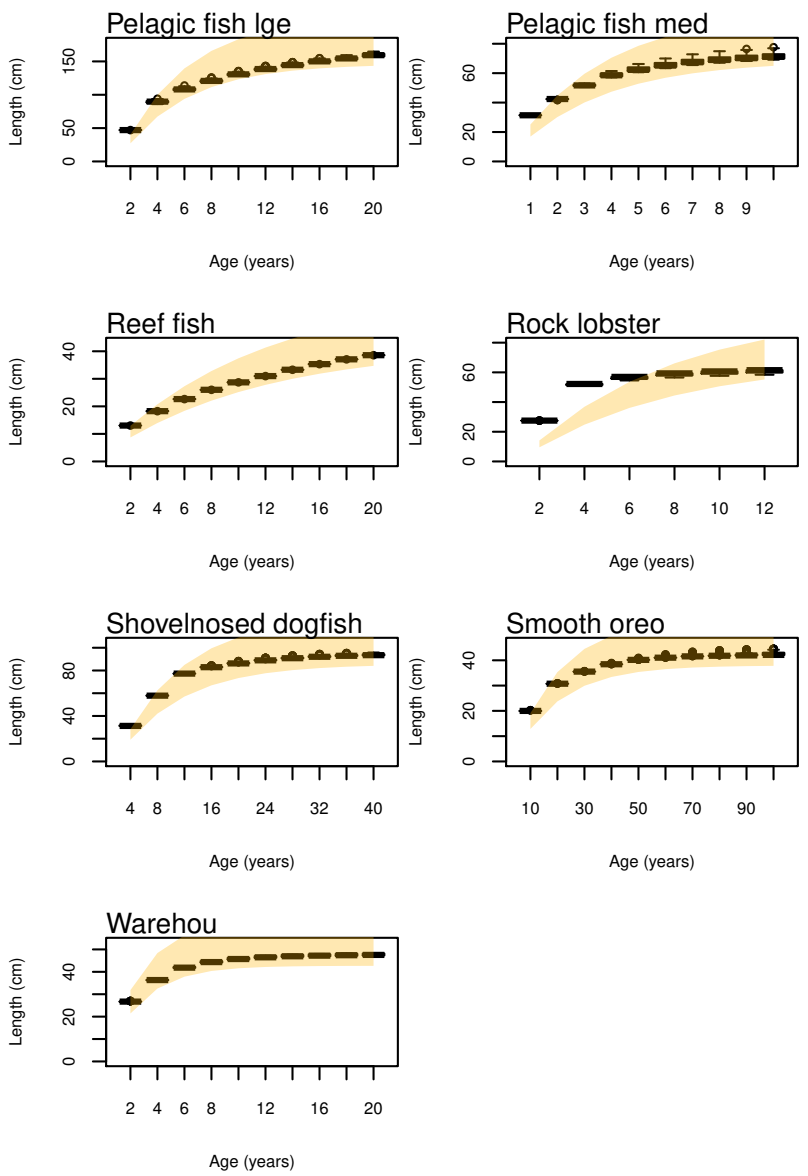

Age (years)

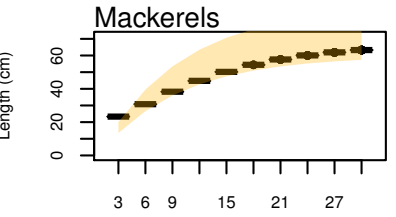

Age (years)

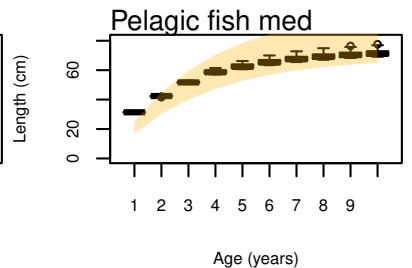



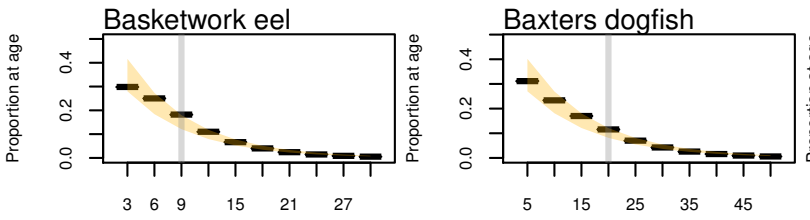

Age (years)

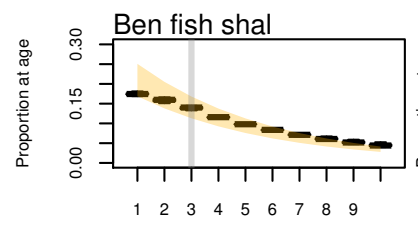

Age (years)
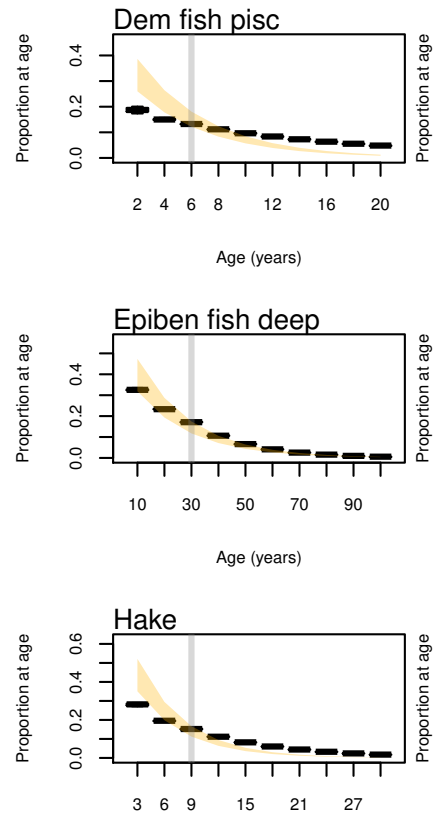

Age (years)

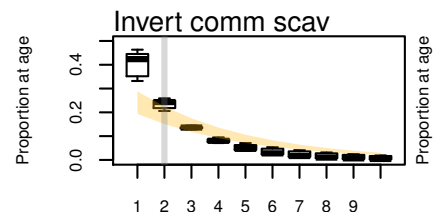

Age (years)
Age (years)

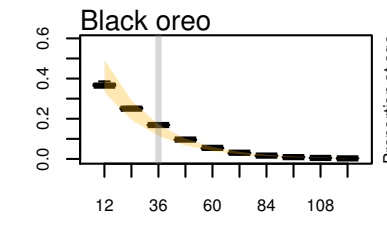

Age (years)

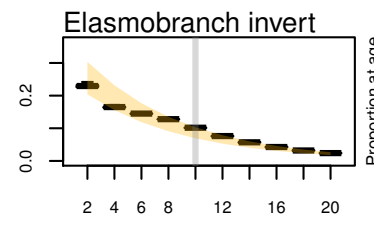

Age (years)

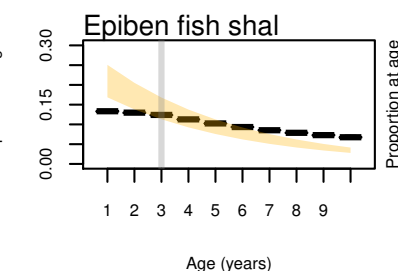

Age (years)

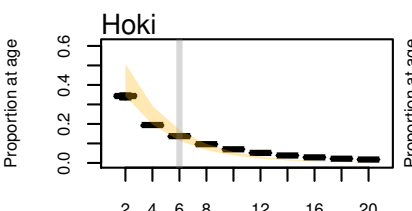

Age (years)

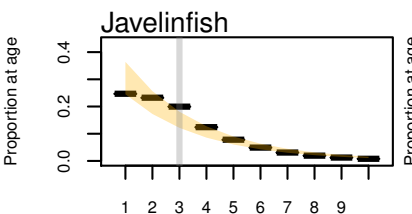

Age (years)

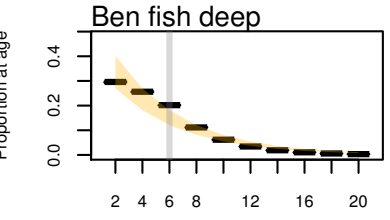

Age (years)

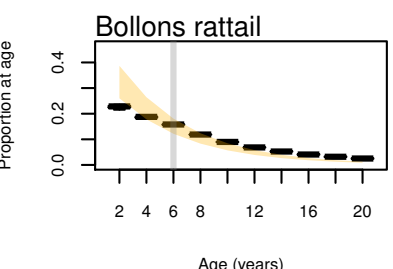

Age (years)
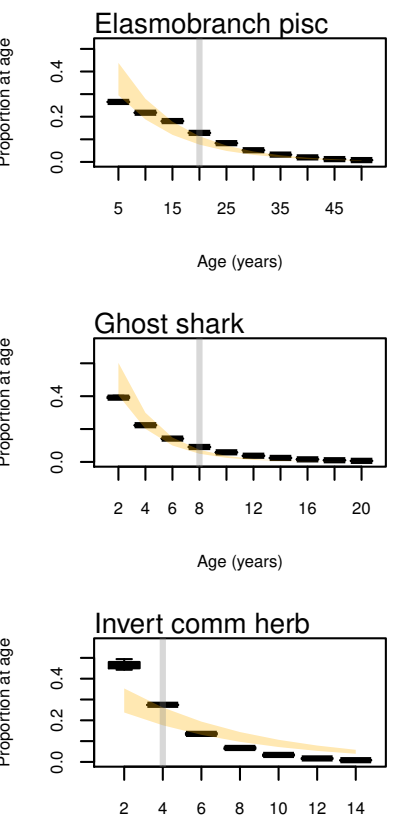

Age (years)

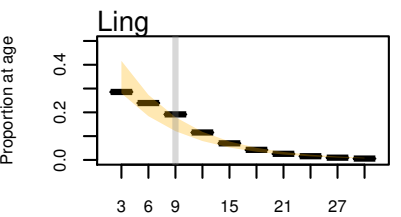

Age (years)

927 


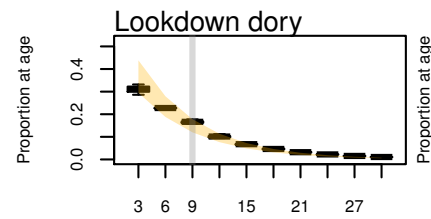

Age (years)
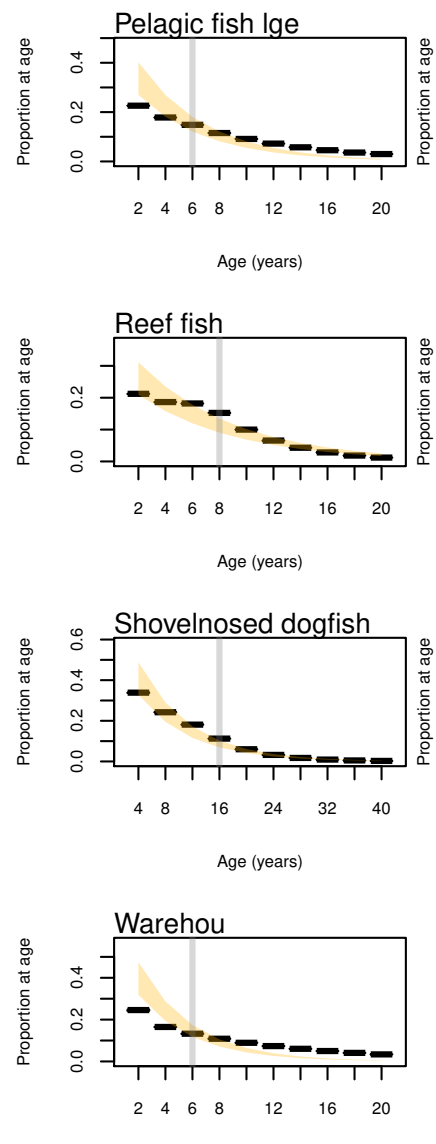

Age (years)

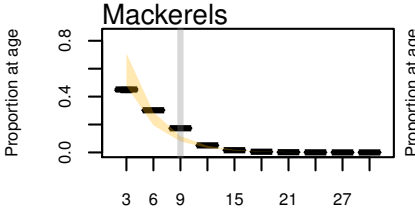

Age (years)

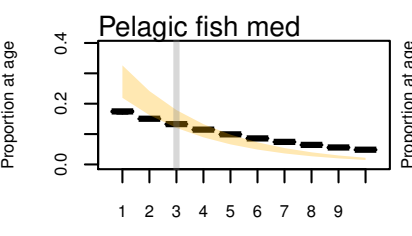

Age (years)

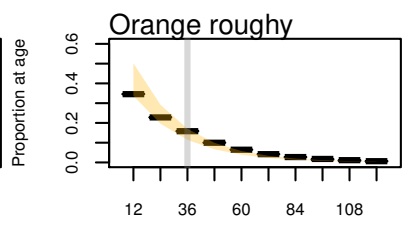

Age (years)

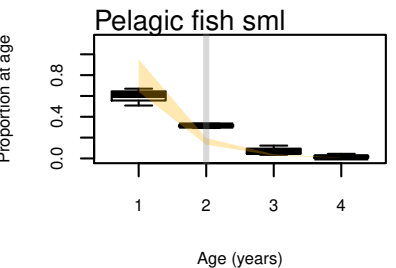

Age (years)
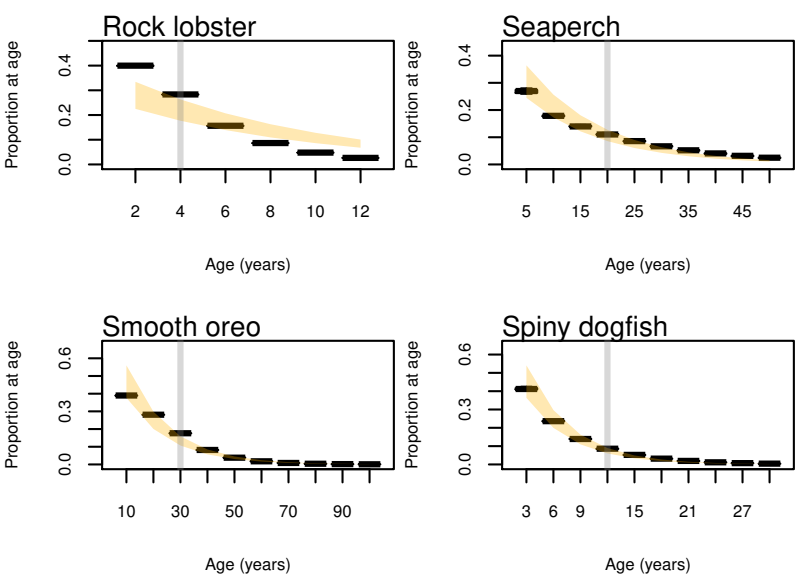

Age (years) 


\section{Appendix D: Observed vs estimated}

Observed biomass estimated from trawl surveys (red), estimated biomass from CRAM

(black) and forced catch history (grey) for all groups with trawl survey estimates.
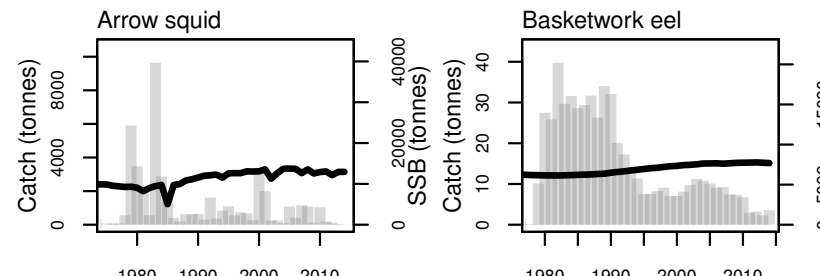

$1980 \quad 1990 \quad 2000 \quad 2010$
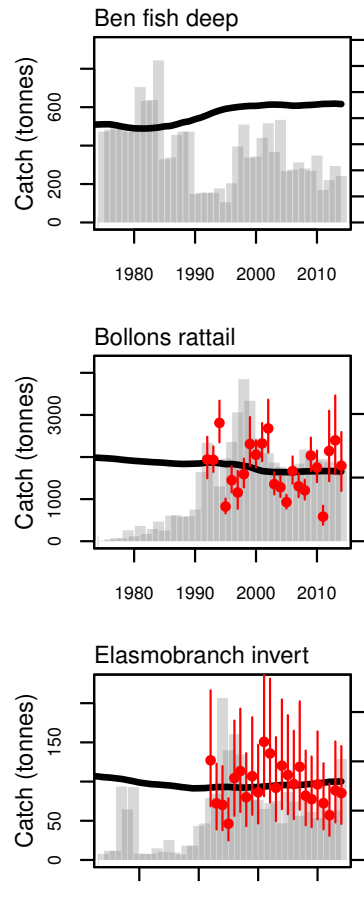

$1980 \quad 19902000 \quad 2010$
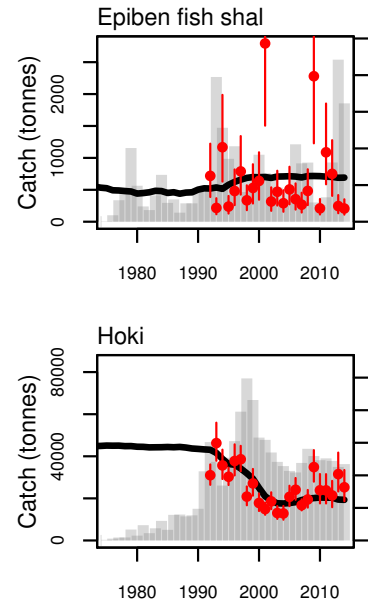

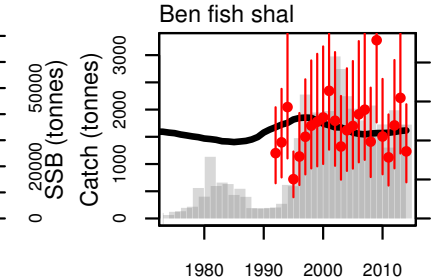

$198019902000 \quad 2010$

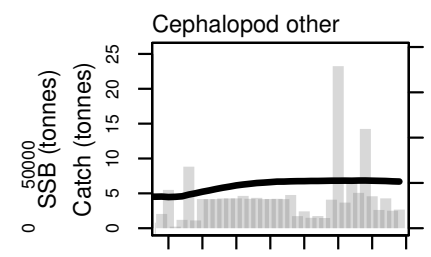

$\begin{array}{llll}1980 & 1990 \quad 2000 \quad 2010\end{array}$

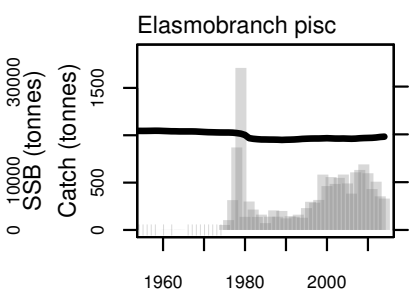

$1960 \quad 1980 \quad 2000$

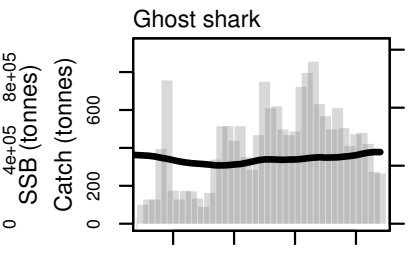

$19801990 \quad 2000 \quad 2010$

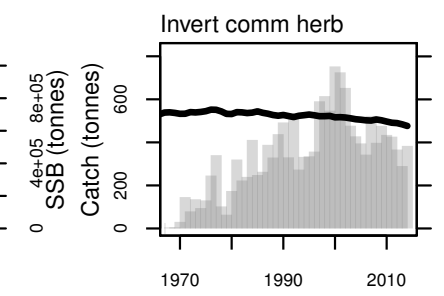

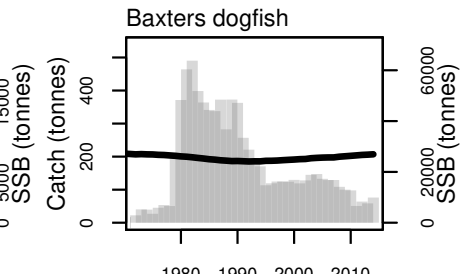

1980199020002010
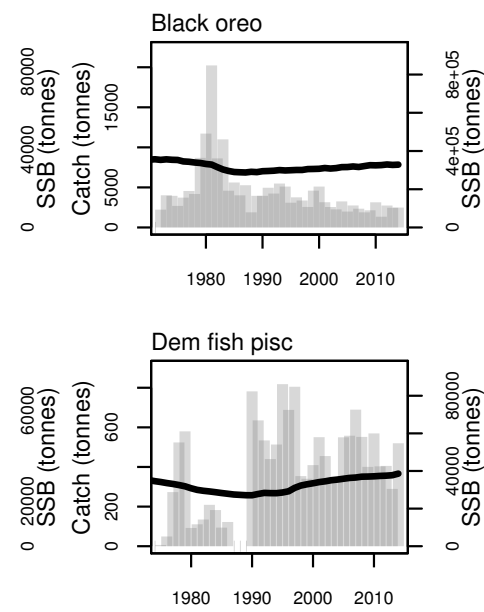

Epiben fish deep
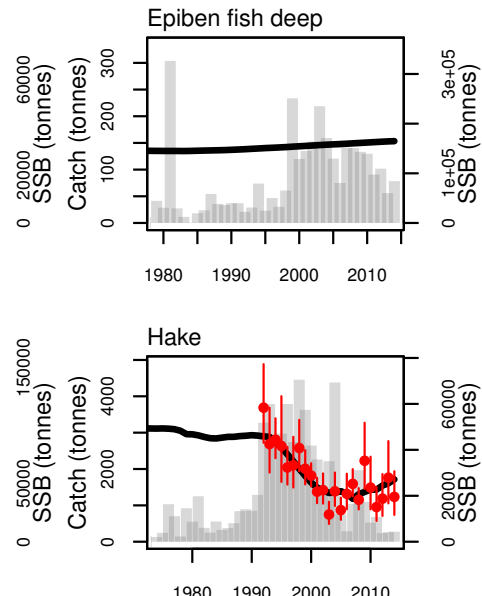

$980 \quad 1990 \quad 2000 \quad 2010$

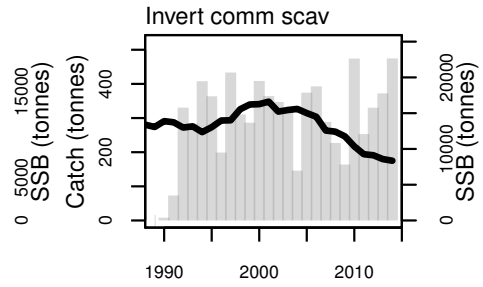



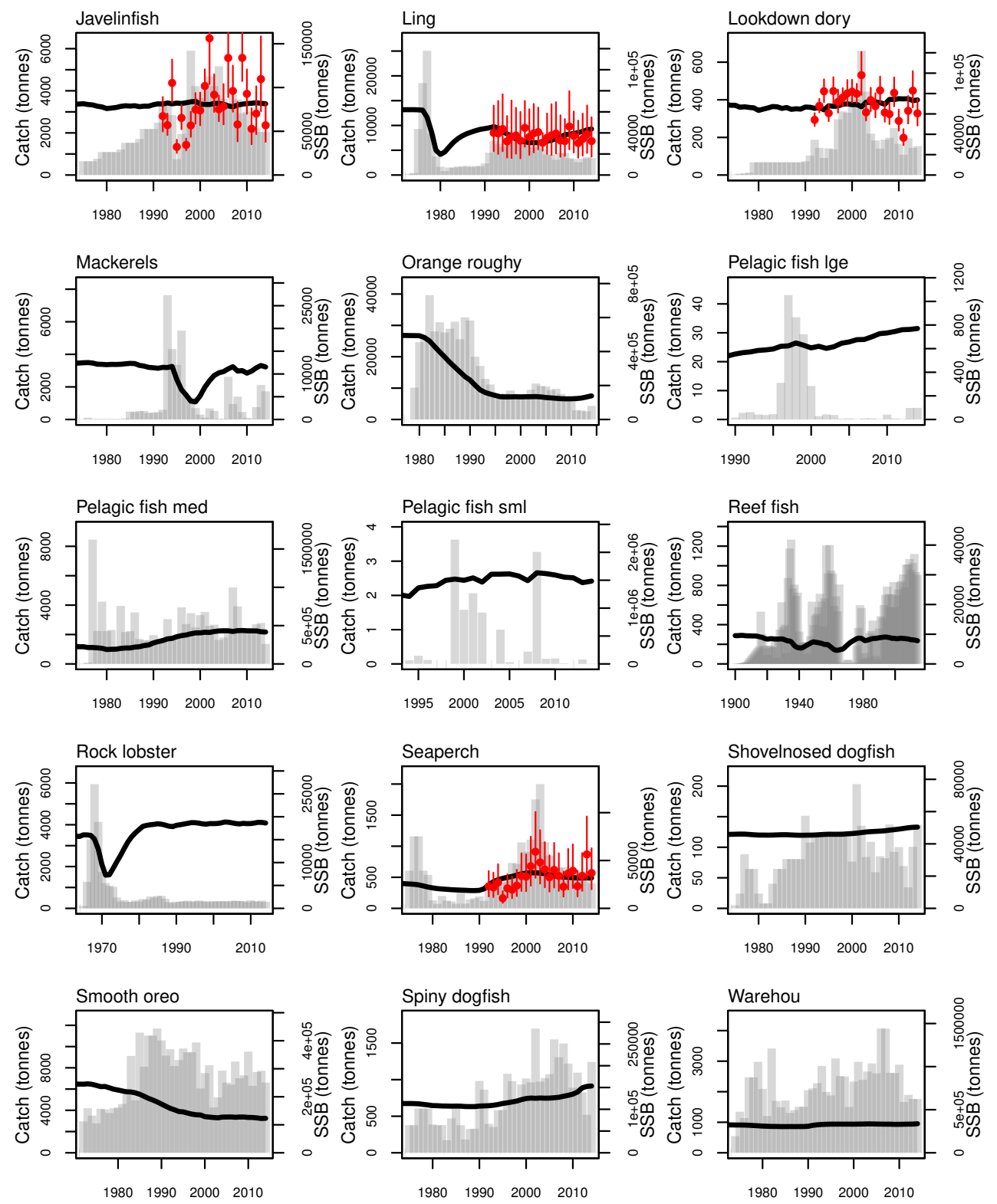